ARTICLE

\title{
Mutant Huntingtin stalls ribosomes and represses protein synthesis in a cellular model of Huntington disease
}

Mehdi Eshraghi (1) ${ }^{1}$, Pabalu P. Karunadharma ${ }^{2}$, Juliana Blin (i) ${ }^{3}$, Neelam Shahani (1) ${ }^{1}$, Emiliano P. Ricci (i) ${ }^{3}$, Audrey Michel ${ }^{4}$, Nicolai T. Urban (10 5, Nicole Galli', Manish Sharma1, Uri Nimrod Ramírez-Jarquín, Katie Florescu', Jennifer Hernandez ${ }^{1} \&$ Srinivasa Subramaniam ${ }^{1 凶}$

The polyglutamine expansion of huntingtin (mHTT) causes Huntington disease (HD) and neurodegeneration, but the mechanisms remain unclear. Here, we found that $\mathrm{mHtt}$ promotes ribosome stalling and suppresses protein synthesis in mouse HD striatal neuronal cells. Depletion of $\mathrm{mHtt}$ enhances protein synthesis and increases the speed of ribosomal translocation, while $\mathrm{mHtt}$ directly inhibits protein synthesis in vitro. Fmrp, a known regulator of ribosome stalling, is upregulated in $\mathrm{HD}$, but its depletion has no discernible effect on protein synthesis or ribosome stalling in HD cells. We found interactions of ribosomal proteins and translating ribosomes with $\mathrm{mHtt}$. High-resolution global ribosome footprint profiling (RiboSeq) and mRNA-Seq indicates a widespread shift in ribosome occupancy toward the $5^{\prime}$ and $3^{\prime}$ end and unique single-codon pauses on selected mRNA targets in HD cells, compared to controls. Thus, $\mathrm{mHtt}$ impedes ribosomal translocation during translation elongation, a mechanistic defect that can be exploited for HD therapeutics.

\footnotetext{
${ }^{1}$ The Scripps Research Institute, Department of Neuroscience, Jupiter, FL, USA. ${ }^{2}$ The Scripps Research Institute, Genomic Core, Jupiter, FL, USA. ${ }^{3}$ Laboratory of Biology and Cellular Modelling at Ecole Normale Supérieure of Lyon, RNA Metabolism in Immunity and Infection Lab, LBMC, Lyon, France. ${ }^{4}$ RiboMaps Ltd, Cork, Ireland. ${ }^{5}$ The Max Planck Neuroscience Institute, Jupiter, FL, USA. ${ }^{凶}$ email: ssubrama@scripps.edu
} 
$\mathrm{R}$ ibosomes move one codon at a time along mRNA during protein synthesis, a fundamental process in all living cells. During this translocation (aka ribosome movement), the ribosomes pause for a variety of reasons, such as codon usage, peptide properties, mRNA structure, and tRNA availability, or solely due to a continuously changing cellular demand ${ }^{1-7}$. This pause can be a transient event (e.g., during the insertion of the signal peptide into the endoplasmic reticulum), or it can be permanent (e.g., during a wrong codon-anticodon pairing $)^{8}$. Regardless, the mechanisms of ribosome pausing (aka ribosome stalling) or its dysregulation in neurodegenerative disease remain poorly understood. Elucidation of the mechanisms governing ribosome stalling should provide an opportunity to develop effective therapeutic interventions.

Ribosome stalling in neurodegenerative disease is associated with several different proteins. For example, GTP-binding protein 2 (GTPBP2), identified after an N-ethyl-N-nitrosourea mutagenesis screen, is known to regulate stalling at the AGA codon, and GTPBP2 deletion promotes a spontaneous ataxia-like neurodegenerative phenotype ${ }^{9}$. Similarly, TAR DNA-binding protein 43 (TDP-43), which promotes amyotrophic lateral sclerosis (ALS) and frontotemporal lobar degeneration (FTLD), interacts with stalled ribosomes during cellular stress and inhibits protein synthesis $^{10,11}$. Mutations in other mRNA-binding proteins (RBPs), such as SMN, FUS, and Ataxin-2 (proteins that also regulate protein synthesis but with unclear mechanisms), can also promote neurodegenerative diseases ${ }^{12-15}$. The Fmrp, another RBP, can bind to ribosomes and regulate ribosome stalling ${ }^{16-18}$. The depletion of Fmr1, as observed in Fragile X syndrome, results in increased protein synthesis that is linked to synaptic and behavioral defects and that can also elicit the neurodegenerative phenotype in Fragile X-associated tremor/ataxia syndrome ${ }^{19,20}$. Deficits in rescuing ribosome stalling may also promote neurodegeneration ${ }^{2,21}$. Major unanswered questions include how ribosome stalling is directly regulated by physiological signals and how its dysregulation affects neurodegenerative disease processes.

Huntingtin (HTT), a ubiquitously expressed protein found throughout the nervous system and in non-neural tissues. Mice with deletion of the Htt gene, $H d h$, die around embryonic day 8.5-10.5 before the full emergence of the nervous system, indicating a role for this gene in cell survival and neurogenesis ${ }^{22-25}$. Conditional deletion of $\mathrm{Htt}$ in the mouse brain results in a defect in corticostriatal development, as well as induces hyperactivity, acute pancreatitis, and age-dependent neurodegenerative-like phenotype $^{26-28}$. These results indicate that normal HTT plays essential role in the organism's developmental and adult brain functions.

The CAG expansion of HTT gene results in mutant HTT (mHTT) protein, which causes Huntington's disease (HD), a debilitative autosomal-dominant brain disorder with worldwide distribution ${ }^{29-31}$. Although mHTT does not appear to perturb development in mouse models, it has been shown to interfere with cortical neurogenesis in the human fetal brain ${ }^{32,33}$.

In humans, HD onset and severity of symptoms depend on the number of CAG repeats in HTT. Brain pathology and magnetic resonance imaging studies show early severe damage to the striatum $^{34-36}$. As the disease progresses, the damage extends to the cortex and multiple CNS and peripheral regions, leading to motor dysfunctions, weight loss, and energy deficits ${ }^{37-40}$. The majority of HD patients are heterozygous, but some homozygous patients experience a severe clinical course, such as rapid striatal atrophy and decline in motor, cognitive, and behavioral skills ${ }^{41,42}$. These HD deficits can emanate from one or more effects of mHTT and its proteolytically cleaved fragments on several functions, such as vesicle- and microtubule-associated protein/organelle transport, transcription, autophagy, and sphingosine and cysteine metabolism, oxidative stress, calcium signaling, as well as effects on tissue maintenance, secretory and inflammatory pathways, and cell division ${ }^{43-69}$. Altered ribosomal functions and association of HTT and mHTT with translating ribosomes were reported in HD model systems and HD patient-tissue ${ }^{51,70-78}$. But the evidence for the role(s) or the mechanism(s) of HTT in the regulation of protein synthesis is limited. Here, we report that $\mathrm{mHtt}$ suppresses protein synthesis via mechanisms involving ribosome stalling potentially occurring during elongation.

\section{Results}

Ribosome stalling and suppression of protein synthesis in HD cells. Protein synthesis is regulated in a cell-type-specific manner; therefore, we employed homogenous HD knock-in cell models for our translation studies ${ }^{79,80}$. We investigated mRNA translation using genetically precise striatal neuronal cells that express a targeted insertion of a chimeric human-mouse exon 1 with $7 / 7$ CAG (STHdhQ7/Q7, control), 7/111 CAG (STHdhQ7/Q111, HDhet), and 111/111 CAG (STHdhQ111/Q111, HD-homo) repeats ${ }^{80}$. We used polysome profiling to estimate mRNA loading onto translating polyribosomes. We identified a high polysome/ monosome (PS/MS) ratio in the HD-homo compared to the HDhet or control cells (Fig. 1A, B) by integrating the area under the curve from raw profiles (Supplementary Fig. S1). We hypothesized that the high $\mathrm{PS} / \mathrm{MS}$ ratio in $\mathrm{HD}$-homo cells reflected a more actively translating mRNA in the HD-homo cells. We examined this possibility by measuring protein synthesis with SUnSET, a nonradioactive puromycin/antibody-based tool ${ }^{81}$. However, we found diminished puromycin incorporation, reflective of reduced mRNA translation (protein synthesis), in the HD-homo $(\sim 40 \%)$ and HD-het cells $(\sim 20 \%)$ compared to the control cells (Fig. 1C, D). As with puromycin, we found diminished incorporation of radiolabeled $\left.{ }^{35} \mathrm{~S}\right]$-methionine into newly synthesized proteins in the HD-homo cells $(\sim 40 \%)$ compared to the control cells (Supplementary Fig. S2). Human HD-het fibroblasts also showed a significant reduction in protein synthesis compared to unaffected controls (Supplementary Fig. S3).

We then hypothesized that the high PS/MS ratio in HD-homo striatal cells, despite the diminished protein synthesis, could reflect a pause in ribosome movements, which would lead to a more diminished rate of translation elongation in the HD-homo than in the control cells. We tested this hypothesis in ribosome run-off experiments with harringtonine, a compound that inhibits the initiation of mRNA translation without affecting the ribosomes that have cleared the start codon ${ }^{82-85}$. Analysis of the ribosome profiling of harringtonine-treated cells, therefore, allows a determination of whether the cells are experiencing ribosome stalling. If ribosomes are stalled, then the profile will show a lower MS peak in cells that are stalled (i.e., cells that have a high PS/MS ratio) than in cells in which ribosomes are not stalled $^{86}$. If ribosomes run faster, then the profile will show an increased MS peak (i.e., cells that have a low PS/MS ratio) than in cells in which ribosomes are moving slower.

We found that harringtonine treatment $(\sim 2 \mathrm{~min})$ resulted in a rapid increase in the $80 \mathrm{~S}$ (MS) peak in control striatal cells (Fig. 1E, arrow) compared to the HD-homo striatal cells. At this point, the polysome profile in the HD-homo cells remained high compared to the control cell profile (Fig. 1E, inset e2; arrowhead). These data indicated that ribosomes ran slower in HD cells than in control cells. After $5 \mathrm{~min}$ of harringtonine treatment, the polysome profile still appeared higher in HD cells than in the control cells (Fig. 1E, inset e3, arrowhead). By $8 \mathrm{~min}$, the ribosomes appeared to have completed their translation (run-off) similarly in both the HD-homo and the control cells (Fig. 1E, inset $\mathrm{e} 4$, arrowhead). The PS/MS ratio between control and HD 


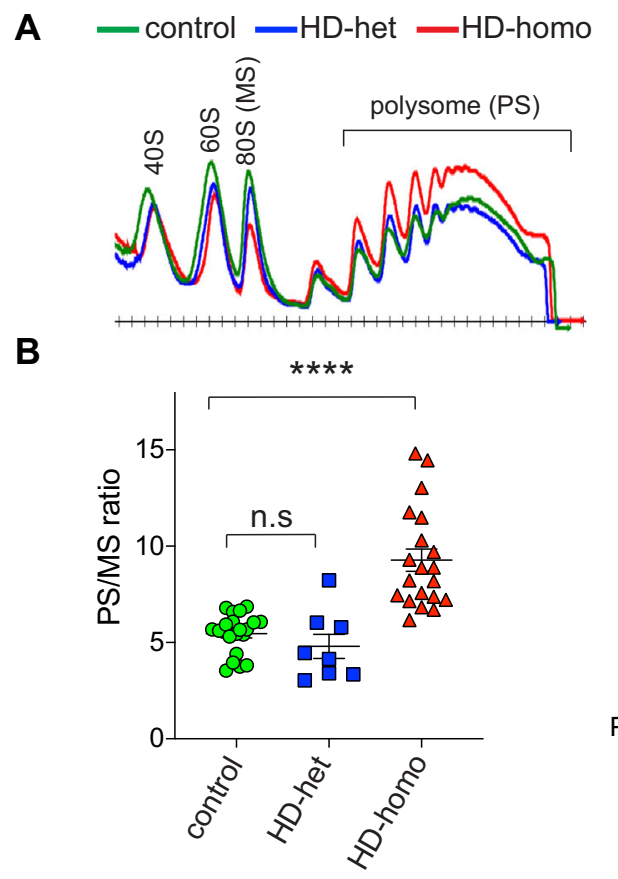

E

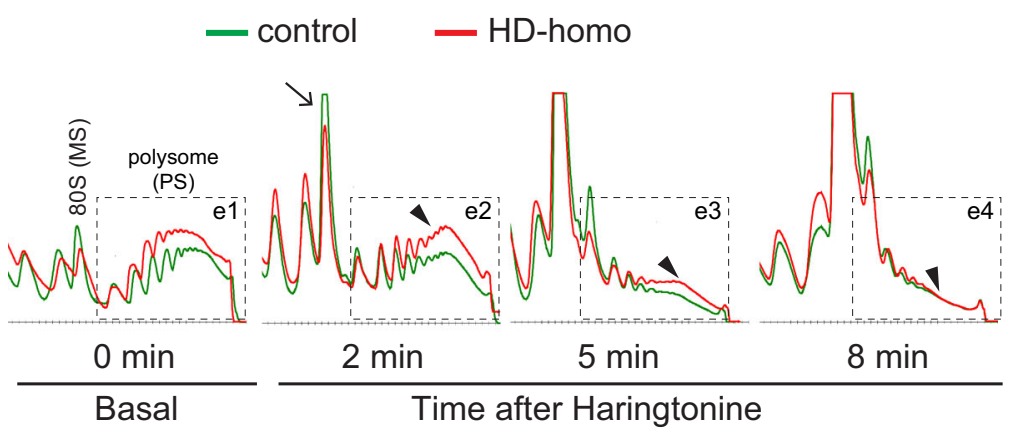

G

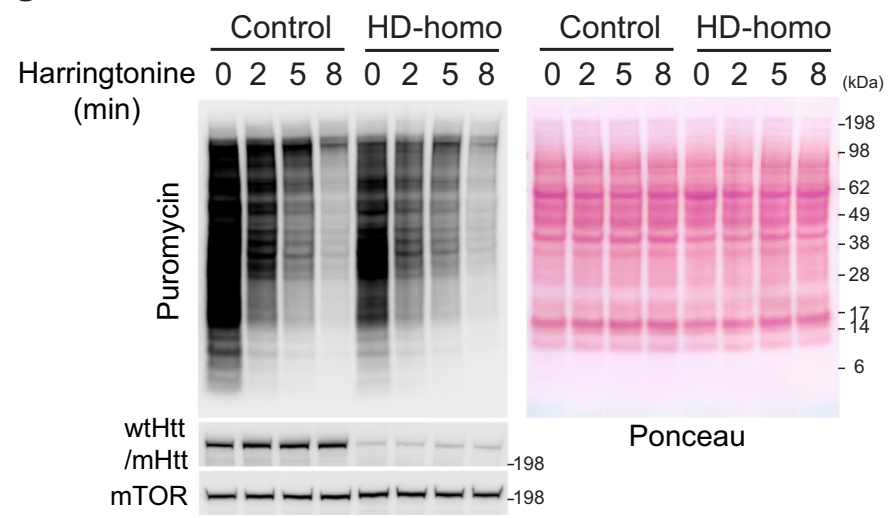

D
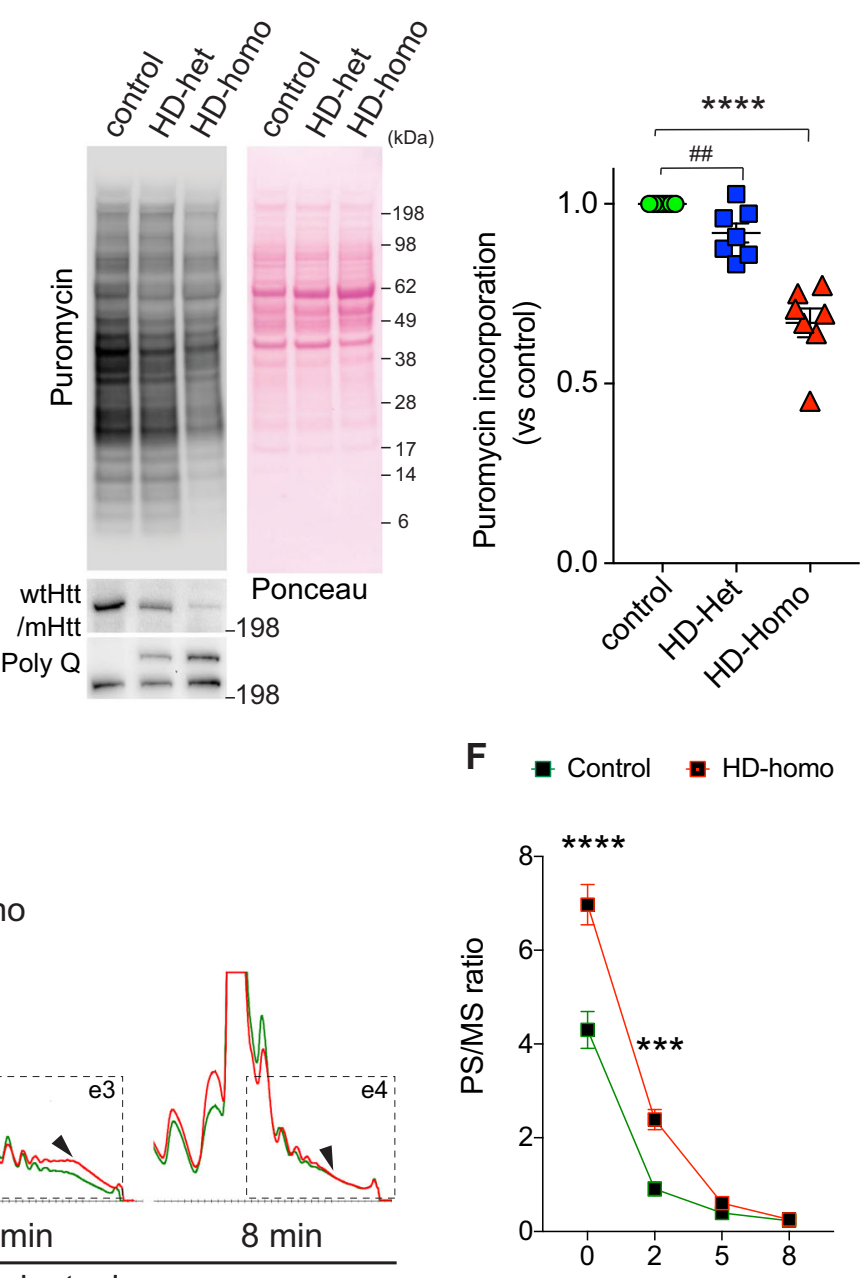

Time after Harringtonine $(\min )$

H

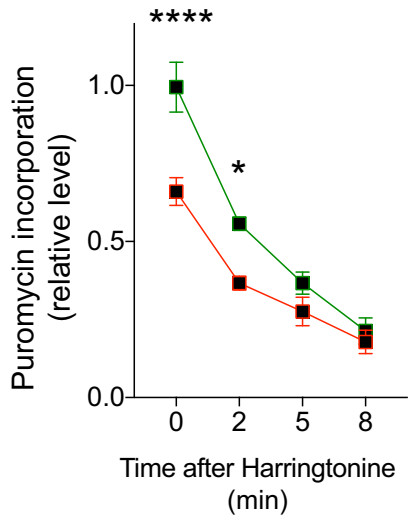

cells showed a significant correlation after the harringtonine treatment (Fig. 1F). Moreover, despite their high PS/MS ratio (Fig. 1E, F), the HD cells showed diminished protein synthesis under the harringtonine treatment (Fig. 1G, H), indicative of stalled and slowly elongating ribosomes in HD.

We also found a much slower ribosome runoff in HD cells than in controls in the presence of puromycin (Supplementary
Fig. S4A, B), another compound that can be employed to assess the ribosome runoff ${ }^{16,87,88}$. Thus, the harringtonine and puromycin experiments both showed that polysome depletion from mRNA occurs much more slowly in HD cells than in control cells. Collectively, these data indicate that the diminished protein synthesis in HD striatal cells potentially occurs due to an inhibition of translational elongation caused by ribosome stalling. 
Fig. 1 Suppression of protein synthesis and ribosome stalling in HD cells. A Representative polysome profile of control, HD-het and HD-homo striatal cells obtained by using sucrose density gradient fractionation. B Quantification of polysome to monosome (PS/MS) ratio in polysome profiles from A (area under the curve). Data are mean \pm SEM (control, $n=20$; HD-Het, $n=8$; HD-Homo, $n=20$ independent experiments) ${ }^{\star \star \star \star} P<0.0001$ by one-way ANOVA followed by Tukey's multiple comparison test. C Representative immunoblots of metabolic labeling of protein synthesis, using puromycin, and its quantification (D) in mouse striatal cells. Ponceau staining of the blots was used to quantify the total protein signal in each lane. Data are mean \pm SEM $(n=$ 7, independent experiments) $\# \# P<0.01$ by two-tailed Student's $t$ test and ${ }^{\star \star *} * P<0.0001$ by one-way ANOVA followed by Tukey's multiple comparison test. E Representative polysome profiles obtained from control and HD-homo striatal cells at basal ( 0 min) and after ribosome run-off assay with harringtonine $(2 \mu \mathrm{g} / \mathrm{ml}, 2,5$, and $8 \mathrm{~min})$. Area e1-e4 shows ribosome movement between control (green) and HD-homo (red) cells. F Quantification of polysome to monosome (PS/MS) ratio in polysome profiles from $\mathbf{E}$ (area under the curve). Data are mean $\pm \mathrm{SEM}$ (at $0 \mathrm{~min}, n=8 ; 2 \mathrm{~min}, n=8 ; 3 \mathrm{~min}, n=$ 4; $8 \mathrm{~min}, n=6$ independent experiments), ${ }^{\star \star \star} P<0.001$ and ${ }^{\star \star \star \star} P<0.0001$, by two-way repeated measures ANOVA, Bonferroni's multiple comparisons test. G Representative immunoblots of metabolic labeling of protein synthesis, using puromycin, in control and HD-homo striatal cells at basal ( 0 min) and 2,5 , and 8 min after harringtonine treatment and quantification $(\mathbf{H})$. Ponceau staining of the blots was used to quantify the total protein signal in each lane. Data are mean $\pm \operatorname{SEM}\left(n=7\right.$, independent experiments), ${ }^{\star} P<0.05$ and ${ }^{\star \star \star \star} P<0.0001$ by two-way repeated measures ANOVA, Bonferroni's multiple comparisons test. Exact $P$ values are reported in the Source Data file. Source data are provided as a Source Data file.

Depletion of Htt enhances protein synthesis and increases the speed of ribosome translocation. We then hypothesized that if $\mathrm{mHtt}$ is directly responsible for inhibiting protein synthesis in striatal neuronal cells, as observed in Fig. 1, then its depletion should increase protein synthesis. We tested this hypothesis using CRISPR/Cas9 tools to deplete wtHtt in control cells and $\mathrm{mHtt}$ in HD-homo cells. We found depletions of $\sim 60 \% \mathrm{wtHtt}$ and $\sim 80 \%$ $\mathrm{mHtt}$ in these cells (Fig. 2A, B). Consistent with Fig. 1C, G, protein synthesis was lower in the CRISPR ctrl HD cells than in the CRISPR ctrl cells; however, depletion of either wtHtt or mHtt resulted in a significant increase in protein synthesis, as measured by puromycin incorporation (Fig. 2A, C). The fold change of the increase in protein synthesis was similar between the wtHtt or mHtt-depleted cells (Fig. 2C). These data indicate that both wtHtt and $\mathrm{mHtt}$ inhibit protein synthesis.

We then hypothesized that the enhancement of protein synthesis by depletion of Htt was accompanied by increased ribosomal movements. We evaluated this possibility by conducting ribosome run-off assays in wtHtt-depleted and mHtt-depleted cells under basal (vehicle) and harringtonine-treated conditions. Under the basal conditions, we found no apparent differences in the ribosome profiles, nor did we note any changes in the PS/MS ratio between the CRISPR ctrl and CRISPR wtHtt-depleted control cells (Fig. 2D, E). By contrast, in the presence of harringtonine, the CRISPR wtHtt-depleted cells showed a more rapid increase in MS peak compared to the wtHtt-intact control cells, as well as a significant decrease in the PS/MS ratio (Fig. 2D, F, arrow). Similarly, under basal conditions, the PS/MS ratio was unaltered in CRISPR ctrl or CRISPR mHtt-depleted HD-homo cells (Fig. 2G, H), but the presence of harringtonine caused a significant decrease in the PS/MS ratio in the CRISPR mHttdepleted HD-homo cells compared to mHtt-intact HD-homo cells (Fig. 2G, I). These data indicate that ribosomes run faster when Htt is depleted.

We next compared the effects of harringtonine treatment on polysome profiles in CRISPR wtHtt versus CRISPR mHttdepleted cells (Fig. 2J). We found a higher PS/MS ratio in harringtonine-treated CRISPR mHtt-depleted cells compared to CRISPR wtHtt-depleted cells (Fig. 2J, K). These data further support the notion that ribosomes run much more slowly in HD cells. Collectively, these data reveal that $\mathrm{mHtt}$ inhibits protein synthesis most likely at the level of elongation by promoting ribosome stalling.

Htt directly inhibits protein synthesis in vitro. We investigated whether Htt can directly modulate protein synthesis. We used recombinant human full-length (FL)-wtHTT (23Q) and FLmHTT (48Q), which were purified from HEK293 cells and appeared $>95 \%$ pure on Coomassie gels (Fig. 3A). We tested the effect of these HTT proteins in a rabbit reticulocyte-based in vitro translation (IVT) assay system that measured luciferase synthesis and activity as the relative luciferase unit (RLU). At a $50 \mathrm{nM}$ concentration, both the FL-wtHTT (23Q) and FL-mHTT (48Q) proteins caused a $\sim 40 \%$ reduction in the RLU, compared to a BSA control (Fig. 3B). At $200 \mathrm{nM}$ concentration, we found $\sim 95 \%$ reduction in the RLU but a significantly stronger inhibition by FL-mHTT (48Q) than by FL-wtHTT 23Q (Fig. 3B). This stronger inhibition at a higher concentration led us to look for a dosedependent effect of HTT proteins on protein synthesis. We found that both FL-wtHTT (23Q) and FL-mHTT (48Q) robustly blocked the luciferase expression (RLU) in a concentrationdependent manner (Fig. 3C). Notably, mHTT failed to inhibit luciferase activity if it was added for $5 \mathrm{~min}$ after the IVT reaction was completed (90 min), suggesting that mHTT actively engages the protein synthesis machinery to inhibit luciferase synthesis. We then tracked luciferase activity at different timepoints during the IVT reaction and found a reduced relative luminescence signal. This reduction was much stronger in the presence of the FL-mHTT (48Q) protein than in the presence of FL-wtHTT (23Q) protein at timepoints of 45 and $75 \mathrm{~min}$ during the IVT assay (Fig. 3D). Collectively, these data consistent with a previous report ${ }^{75}$, indicate that both wtHTT and mHTT can directly inhibit protein synthesis, although the inhibitory effect may be slightly stronger for mHTT than for wtHTT.

Fmrp, a known inhibitor of stalling, is upregulated in HD. Given the evidence that ribosomes were apparently stalled in HD cells, we wanted to identify the nature of the ribosome-bound translating mRNAs, as this knowledge could help in identifying the mRNA transcripts that are stalled as well as in understanding the mechanisms of ribosome stalling in HD. We addressed this by isolating mRNAs from the slowly translating polysomes in HDhomo cells and comparing them to mRNAs from control cells using the harringtonine-based ribosome run-off assay (RRA), followed by mRNA-Seq (PS-RRA-mRNA-Seq) (Fig. 4A). This approach identified $\sim 1157$ targets (Fig. $4 \mathrm{~B}$ and Supplementary Data 1) that showed high mRNA abundance (red dots) and $\sim 1248$ targets that showed low mRNA abundance (blue dots) in the polysome of $\mathrm{HD}$-homo cells $(P<0.05)$ compared to the control polysome. Of these targets, we noticed higher levels of Fmrp (encoded by Fmr1), a known inducer of ribosome stalling ${ }^{18}$, in the PS-RRA-RNA-Seq from the HD-homo cells than from the control cells (Padj=0.01), whereas the levels of Gapdh, $m T O R$, Eif $2 \alpha$, and Rps27 were not significantly altered (Fig. 4C, upper panel). The qPCR analysis of the ribosome fractions (MS and PS) not treated with harringtonine showed similar levels of Fmrl, Gapdh, and Rps27 mRNA in both the control and 
A

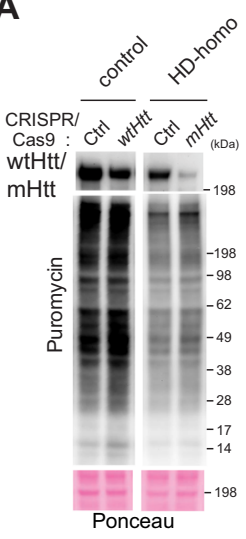

B

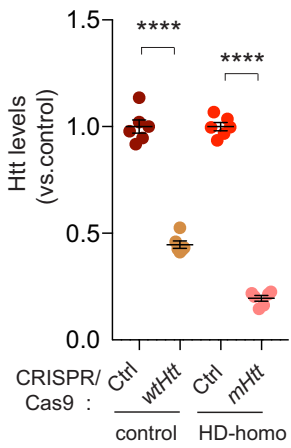

C

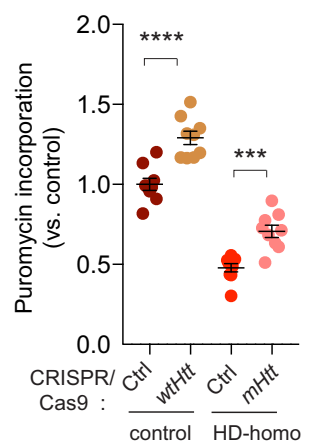

D

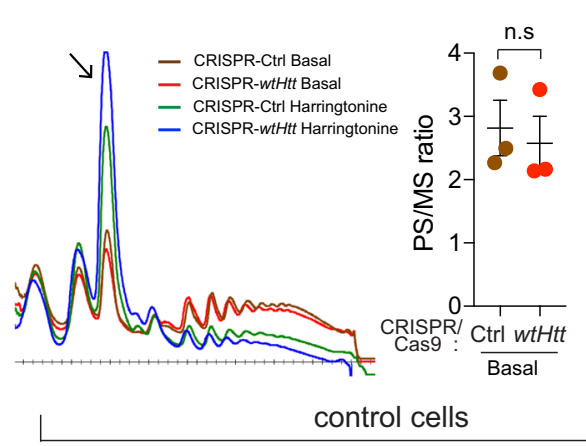

F

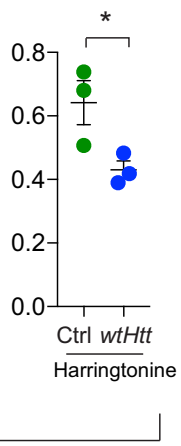

G

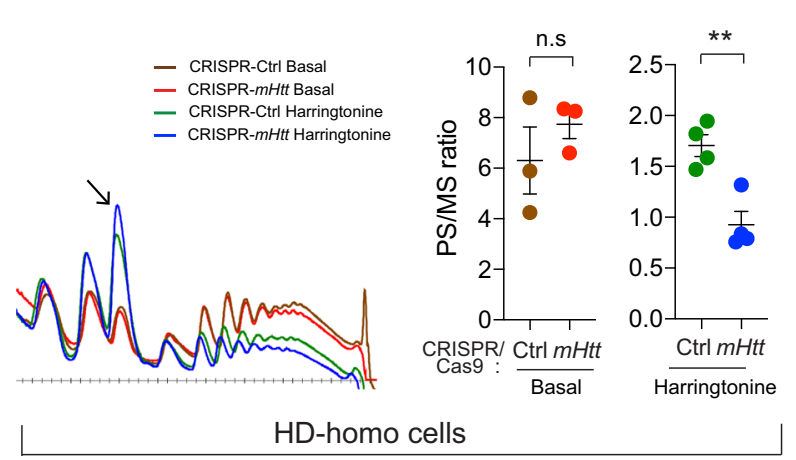

H
I
J

K

Fig. 2 Depletion of $\mathbf{m H t t}$ enhances protein synthesis and increases the speed of ribosome translocation. A Representative immunoblots performed on CRISPR/Cas9 Htt-depleted mouse striatal cells after puromycin metabolic labeling. B, C quantifications of the blots from $\mathbf{A}$ showing levels of Htt (B), puromycin incorporation (C) in control (Ctrl) and Htt-depleted control, HD-homo striatal cells. Data are mean \pm SEM ( $n=9$ independent experiments), ${ }^{\star \star \star} P<0.001$ and ${ }^{\star \star \star \star} P<0.0001$ one-way ANOVA followed by Bonferroni's multiple comparisons test. D-F Representative polysome profiles (D) obtained from wtHtt-depleted mouse striatal cells before (basal, E) and after ribosome run-off assay using harringtonine $(2 \mu \mathrm{g} / \mathrm{ml}, 2 \mathrm{~min}, \mathbf{F})$ and their corresponding quantification of polysome to monosome (PS/MS) ratios (area under the curve). Data are mean \pm SEM ( $n=3$ independent experiments), ${ }^{\star} P<0.05$ by twotailed Student's $t$ test, n.s not significant. G-I Representative polysome profiles (G) obtained from $m H t t$-depleted mouse striatal cells before (basal, $\mathbf{H}$ ) and after ribosome run-off assay using harringtonine ( $2 \mathrm{~min}, \mathbf{I})$ and their corresponding quantification of polysome to monosome (PS/MS) ratios (area under the curve). Data are mean $\pm \operatorname{SEM}\left(\mathbf{H}, n=3 ; \mathbf{I}, n=4\right.$ independent experiments), ${ }^{\star \star} p<0.01$ by two-tailed Student's $t$ test, $n . s$ not significant. $\mathbf{J}, \mathbf{K}$ Representative polysome profiles ( $\mathbf{J}$ ) obtained from wtHtt- and $\mathrm{mHtt}$-depleted mouse striatal cells after ribosome run-off assay using harringtonine (2 min), and their corresponding quantification of polysome to monosome (PS/MS) ratios (K). Data are mean \pm SEM ( $w t H t t$ depleted, $n=5 ; m H t t$ depleted, $n=6$ independent experiments), ${ }^{\star} P<0.01$ by two-tailed Student's $t$ test. n.s not significant. Exact $P$ values are reported in the Source Data file. Source data are provided as a Source Data file.

HD-homo cells. These results indicate that Fmr1 mRNA strongly binds to ribosomes in HD (Fig. 4C, lower panel).

Because Fmr1 mRNA is associated with polysomes in HD cells, we hypothesized that Fmr1 mRNA is stalled in HD and that its protein levels should be low. However, contrary to this assumption, we found that Fmrp protein levels were significantly upregulated in the HD-homo cells, as well as in human HD patient striatum, whereas the total Fmr1 mRNA was differentially altered (Fig. 4D, E). Collectively, PS-RRA-mRNA-Seq data suggested that Fmrp is upregulated in HD.

Fmrp does not affect mHtt-mediated protein synthesis or ribosome stalling in $\mathrm{HD}$ cells. As Fmrp is upregulated in HD and is a known inducer of ribosome stalling, we hypothesized that Fmrp is likely involved in ribosome stalling in HD cells. We examined the role of Fmrp using CRISPR-Fmr1 to deplete Fmr1 in control and HD-homo cells; this resulted in $\sim 80 \%$ reduction in the Fmrp protein levels (Fig. 5A, B). We found that Fmrp depletion in control cells increased protein synthesis, as measured by enhanced puromycin incorporation, whereas, surprisingly, it had no discernable effect on protein synthesis in the HD-homo cells (Fig. 5A, C).

We further dissected the Fmrp role in HD cells by generating a double knockout of $\mathrm{mHtt} / \mathrm{Fmrp}$, using CRISPR/Cas9. We found that cells in which $\mathrm{mHtt}$ alone were depleted showed a significantly increased protein synthesis, whereas cells in which Fmrp alone was depleted or in which both mHtt and Fmrp were depleted showed protein synthesis levels similar to those of cells in which mHtt alone was depleted (Fig. 5D, E). We then used harringtonine to examine whether Fmrp depletion had any effect on ribosome stalling in HD cells. The mHtt depletion enhanced the ribosome runoff (Fig. 5F, G), as before (Fig. 2G, I). However, Fmrp depletion did not significantly alter the ribosome runoff (Fig. 5F, G). These data indicated that (i) Fmrp upregulation might not impact overall protein synthesis inhibition in the cultured HD cells, and (ii) mHtt acts upstream or independently of Fmrp to promote ribosome stalling and inhibit protein synthesis in HD cells. 

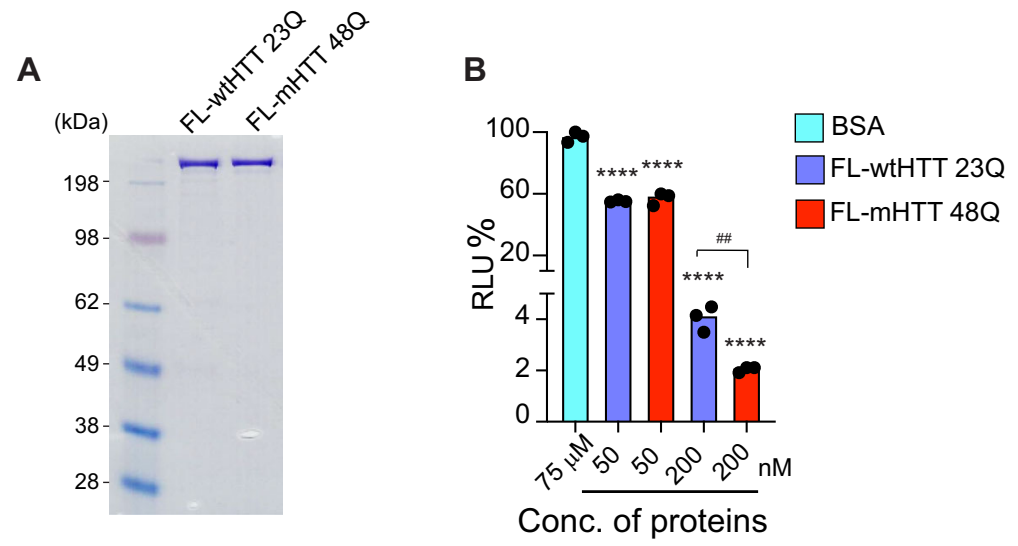

C

BSA $\square$ FL-wtHTT 23Q $\square$ FL-mHTT 48Q
D
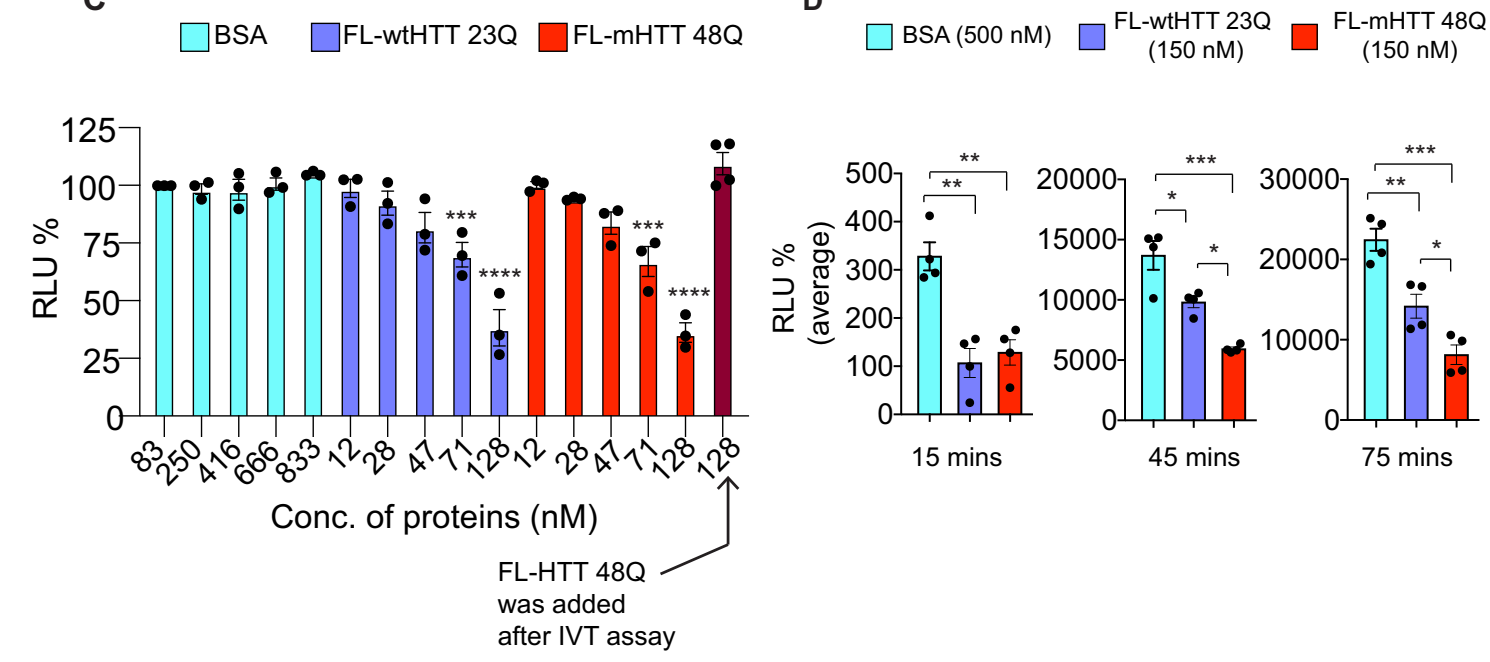

Fig. 3 mHTT inhibits protein synthesis in vitro. A Coomassie gel showing FL-wtHTT $23 \mathrm{Q}$ (250 ng) and FL-mHTT $48 \mathrm{Q}$ ( $250 \mathrm{ng}$ ), $n=3$ independent experiments. B Shows the percentage of relative luciferase unit (RLU) in presence of an indicated concentration of recombinant FL-wtHTT and FL-mHTT. HTT proteins normalized to the maximum luminescence in BSA $(75 \mu \mathrm{M})$. Data are mean \pm SEM $\left(n=3\right.$ independent experiments). ${ }^{\star \star \star \star} P<0.0001$ by oneway ANOVA followed by Tukey's multiple comparison test. $\# \#<0.01$ by two-tailed Student's $t$ test. $\mathbf{C}$ In vitro translation (IVT) assay in presence of different concentrations of recombinant FL-wtHTT $23 \mathrm{Q}$ and FL-mHTT 48Q or BSA. Bar graphs depict the percentage of relative luciferase unit (RLU) normalized to the maximum luminescence in BSA $(83 \mathrm{nM})$. Data are mean \pm SEM $\left(n=3\right.$ independent experiments). ${ }^{\star \star \star} P<0.001,{ }^{\star \star \star \star} P<0.0001$ by oneway ANOVA followed by Bonferroni's multiple comparisons test. D Shows luciferase activity at 15, 45, and 75 min of IVT reaction with $150 \mathrm{nM}$ recombinant FL-wtHTT $23 \mathrm{Q}$ and FL-mHTT $48 \mathrm{Q}$ proteins or BSA $(500 \mathrm{nM})$. Data are mean $\pm \mathrm{SEM}\left(n=4\right.$ independent experiments). ${ }^{\star} P<0.05,{ }^{\star \star} P<0.01$, ${ }^{\star \star \star} P<0.001$, by one-way ANOVA followed by Tukey's multiple comparison test. Exact $P$ values are reported in the Source Data file. Source data are provided as a Source Data file.

mHtt interacts with ribosomes. We next determined whether $\mathrm{mHtt}$ associates directly with ribosomes to regulate stalling by using multiple approaches. We isolated fractions from the ribosome profiles of control and HD-homo cells treated with vehicle or harringtonine (Fig. 6A). We found that wtHtt and $\mathrm{mHtt}$ both co-sedimented with the 40S, 60S, and 80S (MS) ribosomal subunits and with polysomes in sucrose gradients (Fig. 6A). Similarly, Fmrp, Rpl7, and Rpl35A (which are all known ribosomebinding proteins) also sedimented with the ribosomal subunits and polysome fractions (Fig. 6A). In the presence of harringtonine, which disassembles the polysomes ${ }^{82,85}$, we found a clear increase in the monosome fraction in the ribosome profiling (Fig. 6A, arrowhead). Both wtHtt and $\mathrm{mHtt}$ re-sedimented from the higher-density polysome fractions (\# 6, 7, or 8) to lowerdensity fractions (\# 3, 4, or 5, asterisk) after harringtonine treatment. The known polysome-associated proteins, such as Fmrp, Rpl7, and Rpl35A, also re-sedimented to lower-density fractions (\# 4, 5, or 6) after harringtonine treatment (Fig. 6A). The enhanced band intensity in fraction \# 5 of harringtonine- treated controls cells may be due to the overloading of monosome-accumulated proteins from the collected fractions. Besides, the shifting of ribosomal proteins Rpl7 and Rpl35A to the lower-density fractions appears very slight compared to $\mathrm{Htt}$, which may be because Htt is less abundant on polysomes than ribosomal proteins. These results suggest that wtHtt and $\mathrm{mHtt}$ bind to translating polysomes.

Super-resolution stimulated emission depletion (STED) microscopy studies revealed that $\sim 25-35 \%$ of wtHtt and $\mathrm{mHtt}$ clusters were in proximity $(<300 \mathrm{~nm})$ to the Rpl7 (Fig. 6B, the full image in Supplementary Fig. S5). We saw clear differences between the control and HD-homo cells when calculating the Manders colocalization coefficients (Fig. 6C). We also immunoprecipitated (IP) Htt using MAB2166 antibody and found that Rps6 and Rpl7 showed a stronger co-immunoprecipitation in Htt from HD-het and HD-homo cells than from control cells (Fig. 6D). As a positive control, we detected Caprin1, a previously known interactor of $\mathrm{mHtt}$ (Fig. 6D) ${ }^{75,89}$. Thus, the interaction with ribosomal proteins is stronger for $\mathrm{mHtt}$ than for wtHtt. 
A

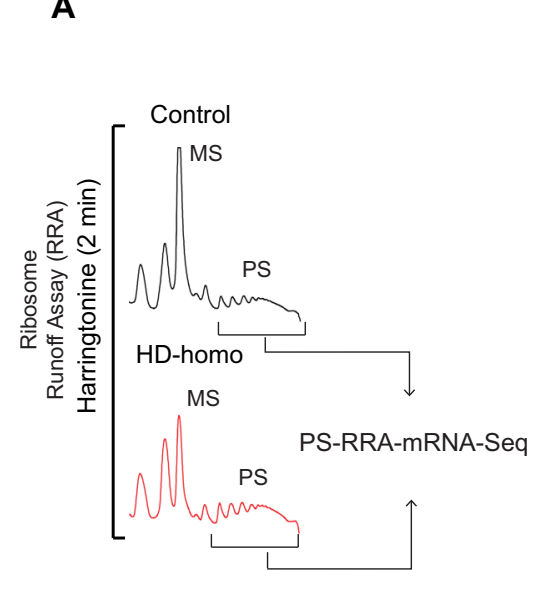

D
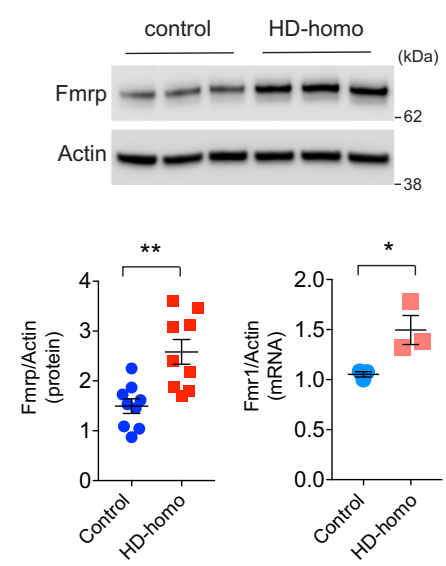

B

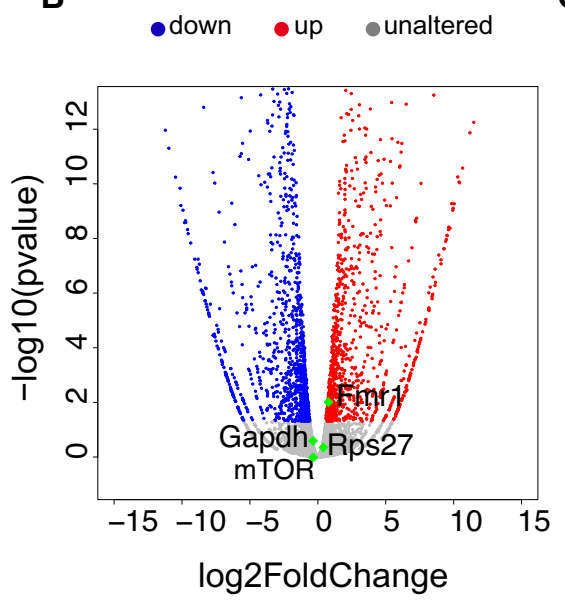

C

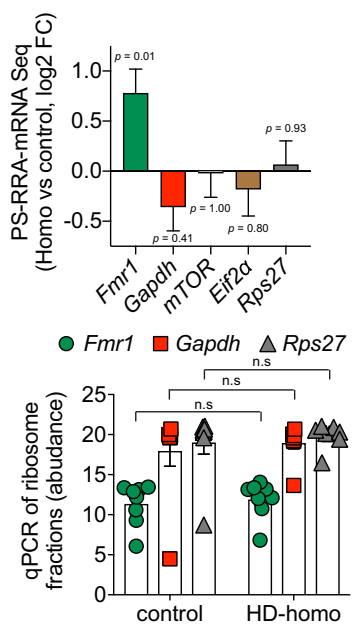

E

HD human striatum
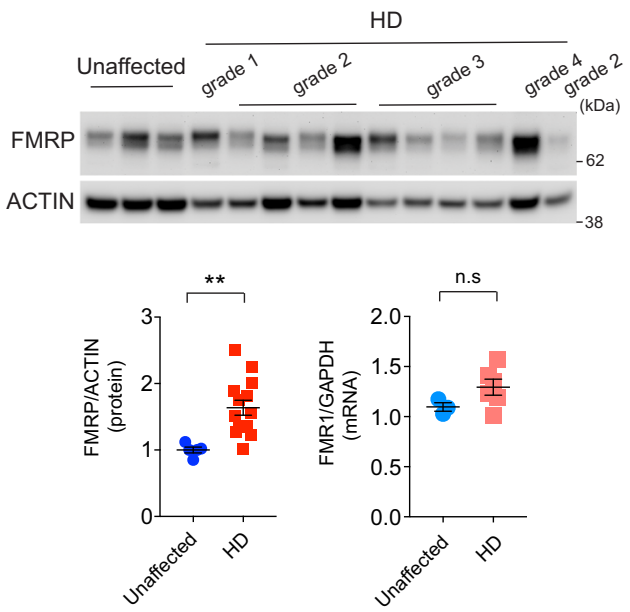

Fig. 4 Fmrp is upregulated in HD. A Representative polysome profiles of control and HD-homo cells after ribosome run-off assay using Harringtonine $(2 \mu \mathrm{g} / \mathrm{ml}, 2 \mathrm{~min})$. mRNA-Seq was performed using RNAs isolated from polysome containing fractions (arrows). B Volcano plot representing changes in gene expression levels of ribosome-bound mRNAs in HD-homo cells (vs control cells) after ribosome run-off assay from $\mathbf{A}$. mRNA transcripts with absolute log2 fold change $(\log 2 F C)>0.3$ and FDR-corrected $P$ value $<0.05$ are shown with red (up, increased polysome binding, $\log 2 F C>1$ ), blue (down, decreased polysome binding, $\log 2 \mathrm{FC}<1$ ), gray (unaltered, no difference in polysome binding) and green (selected targets). Statistical testing was done using DESeq2 with a two-tailed Wald test and adjusted for multiple comparisons using the procedure of Benjamini-Hochberg. C A bar plot representing log2FC in the mRNA levels of some known translation regulating genes within polysome fractions obtained from HD-homo cells (comparing to controls) after ribosome run-off assay (upper panel, Data are $\log 2 \mathrm{FC}$ and the standard error of the $\log 2 \mathrm{FC}$ value from $n=2$ independent experiments), and qPCR of the indicated targets in the purified ribosome fractions (bottom panel, Data are mean \pm SEM, $n=8$ independent experiments, n.s. not significant by two-way ANOVA, Bonferroni's multiple comparisons test). D, E Representative blots and mRNA levels and corresponding quantifications for Fmrp in mouse control and HDhomo striatal cells (Fmrp protein: $n=9$ independent experiments, Fmrp mRNA: $n=3$ independent experiments, D), and unaffected and human HD patient striatum (Fmrp protein: $n=5$ unaffected, $n=14 \mathrm{HD}, F M R P$ mRNA: $n=3$ unaffected, $n=6 \mathrm{HD}$, E). Data are mean \pm SEM, ${ }^{\star} P<0.05,{ }^{\star \star} P<0.01$ by two-tailed Student's $t$ test, n.s not significant. Exact $P$ values are reported in the Source Data file. Source data are provided as a Source Data file.

We asked whether mHtt could directly interact with translating ribosomes. We incubated purified recombinant human HTT proteins (GST-Exon 1-23Q or GST-Exon 1-51Q) ${ }^{90}$ with polysomes isolated from Htt-depleted striatal cells (CRISPR/Cas9-Htt cells, Fig. 2A), and reran the isolated polysomes on a sucrose gradient (flow chart in Supplementary Fig. S6). We found stronger binding to the extracted polysomes with mHTT-51Q than with wtHTT-23Q (Fig. 6E), indicating that poly-Q expansion of HTT may increase HTT avidity toward ribosomes. However, we cannot rule out the possibility that the interaction of HTT with ribosomes may be enhanced in vivo by additional interactors and/or post-translational modifications.

To test this, we carried out whether mHTT bind to ribosomes in human HD-het fibroblasts, under acute amino acid starvation, which produces substantial transcriptional and translational changes. Human HD and healthy fibroblasts were either starved for amino acids (Krebs buffer) or starved and then stimulated with L-leucine (Leu), followed by immunoprecipitation with HTT IgG and control IgG and subjected to mass spectrometry (IP-LCMS/MS) analysis. We found that HTT and mHTT both interacted with several $40 \mathrm{~S}$ and $60 \mathrm{~S}$ ribosomal proteins both in the starved and amino acid-stimulated conditions (Fig. 6F) in healthy and HD fibroblasts. STRING analysis found an enrichment of the biological process and components related to the translation and ribosome/RNA binding (Supplementary Fig. S7A, B). Full interactome data can be found in Supplementary Data 2 (see "Data availability" for protein database). Collectively, the above data demonstrate that $\mathrm{Htt}$ binds to translating ribosomes 
A

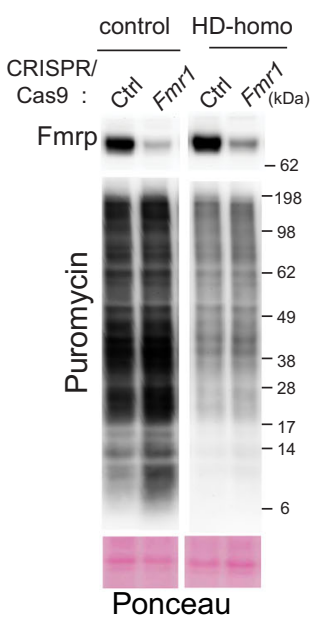

B

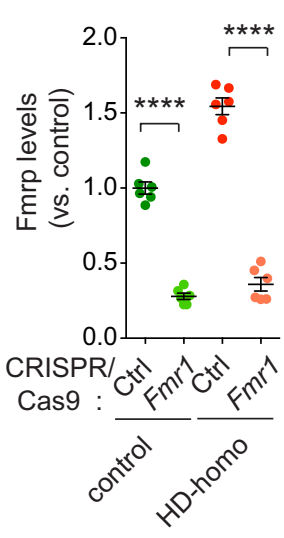

C

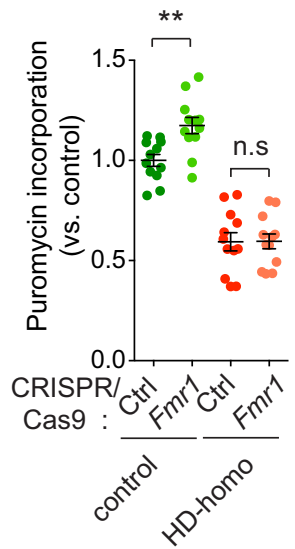

D

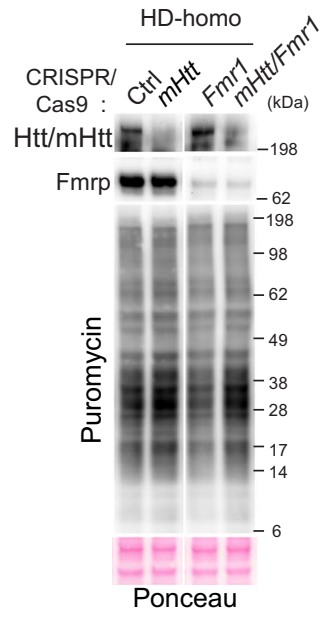

E

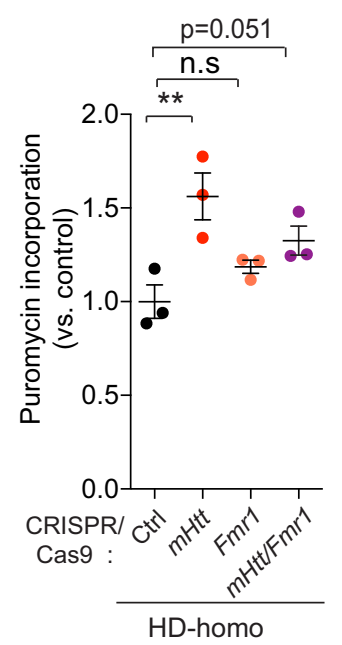

F

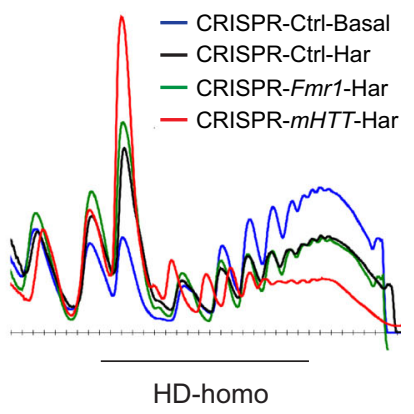

G

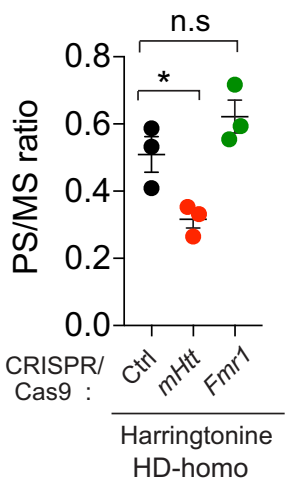

Fig. 5 Fmr1 depletion has no discernible effect on protein synthesis or ribosome stalling in HD cells. A Representative immunoblots performed on CRISPR/Cas9 control (Ctrl) and Fmr1-depleted mouse striatal cells after puromycin metabolic labeling. B, C Quantification of blots from A showing FMRP levels (B), puromycin incorporation (C) in control (Ctrl) and Fmr1-depleted control, and HD-homo striatal cells. Data are mean \pm SEM, $(\mathbf{B} n=6 ; \mathbf{C} n=12$ independent experiments), ${ }^{\star \star} P<0.01,{ }^{\star \star \star \star} P<0.0001$, by one-way ANOVA followed by Bonferroni's multiple comparisons test, n.s not significant. $\mathbf{D}$ Representative immunoblots performed on $\mathrm{Htt}$ or Fmr1 depleted, or Htt/Fmr1 double-depleted HD-homo cells after puromycin metabolic labeling. E Quantification of the blots from $\mathbf{D}$, showing puromycin incorporation. Data are mean $\pm \operatorname{SEM}\left(n=3\right.$ independent experiments), ${ }^{\star \star} P<0.01$, by one-way ANOVA followed by Bonferroni's multiple comparisons test. $P=0.051$ by two-tailed Student's $t$ test. $\mathbf{F}$, $\mathbf{G}$ Representative polysome profiles (F) obtained from $\mathrm{mHtt}$ or Fmr1-depleted mouse striatal cells before (basal) and after ribosome run-off assay using harringtonine $(2 \mu \mathrm{g} / \mathrm{ml}, 3 \mathrm{~min})$ and their corresponding quantification (G) of polysome to monosome (PS/MS) ratio (area under the curve). Data are mean \pm SEM ( $n=3$ independent experiments), by one-way ANOVA followed by Tukey's multiple comparison test. n.s. not significant. Exact $P$ values are reported in the Source Data file. Source data are provided as a Source Data file.

and ribosomal proteins in $\mathrm{HD}$ mouse striatal neuronal cells as well as human HD fibroblasts.

Global ribosome profiling reveals diverse $5^{\prime}$ and $3^{\prime}$ ribosome occupancy on mRNA transcripts in HD cells. The indications that $\mathrm{mHtt}$ binds and stalls ribosomes led us to posit that overall global ribosome occupancy may be altered in HD. We investigated this using a global ribosome profiling approach ${ }^{91-94}$. We treated cells with cycloheximide, as described previously 95,96 , and isolated polysomes from three biological replicates of wild-type control striatal cells and HD-het and HD-homo mutant striatal cells. We conducted ribosome profiling to prepare ribosome footprints (Ribo-Seq) and matching RNA (RNA-Seq) (Supplementary Fig. S8). Multiple quality control measures, such as principal component analysis (Fig. 7A) and Euclidian distance analyses (Supplementary Fig. S9A), showed that the replicates were very similar, with genotype as the principal source of differences between the control and the HD cells. Most of the differential ribosome occupancies (ribosome-protected fragments, RPF) were mapped to annotated protein-coding open-reading frames, with a 29-nt expected triplet nucleotide periodicity and ribosome occupancy at the start and stop codon for control, HD-het, and HD-homo (Fig. 7B and Supplementary Fig. S9B, C). Thus, we generated a high-quality Ribo-Seq library of control, HD-het, and HD-homo striatal cells for subsequent bioinformatics analysis. 
A
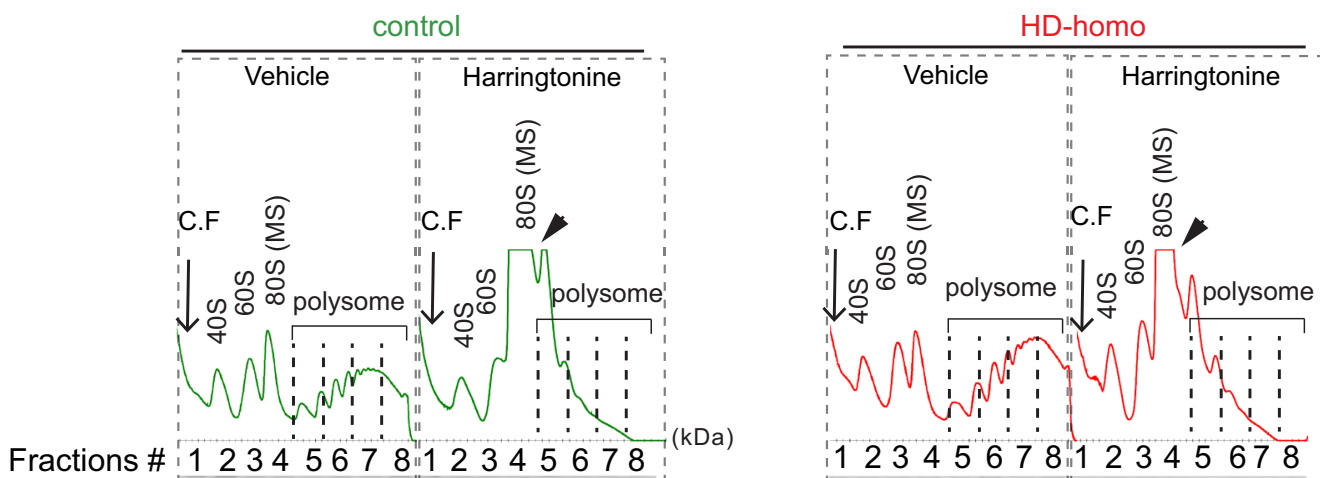

$(\mathrm{kDa})$

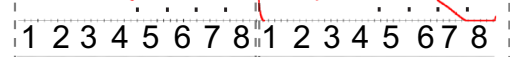

$(\mathrm{kDa})$

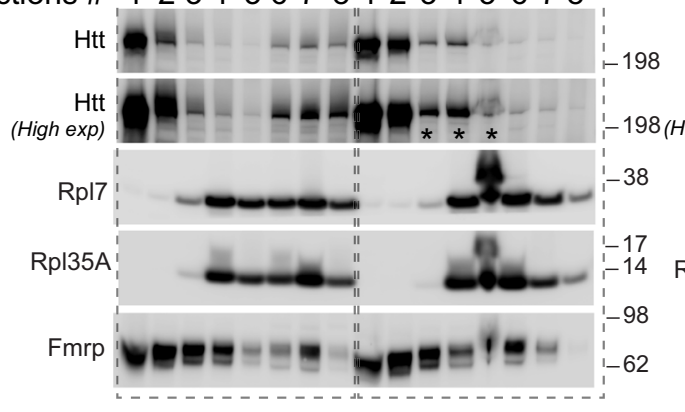

B
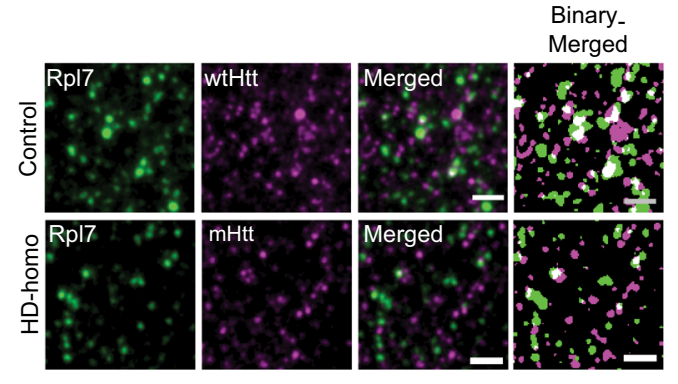

D

IP

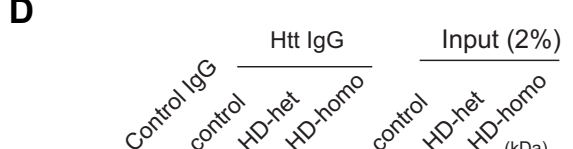

E

$\mathbf{F}$
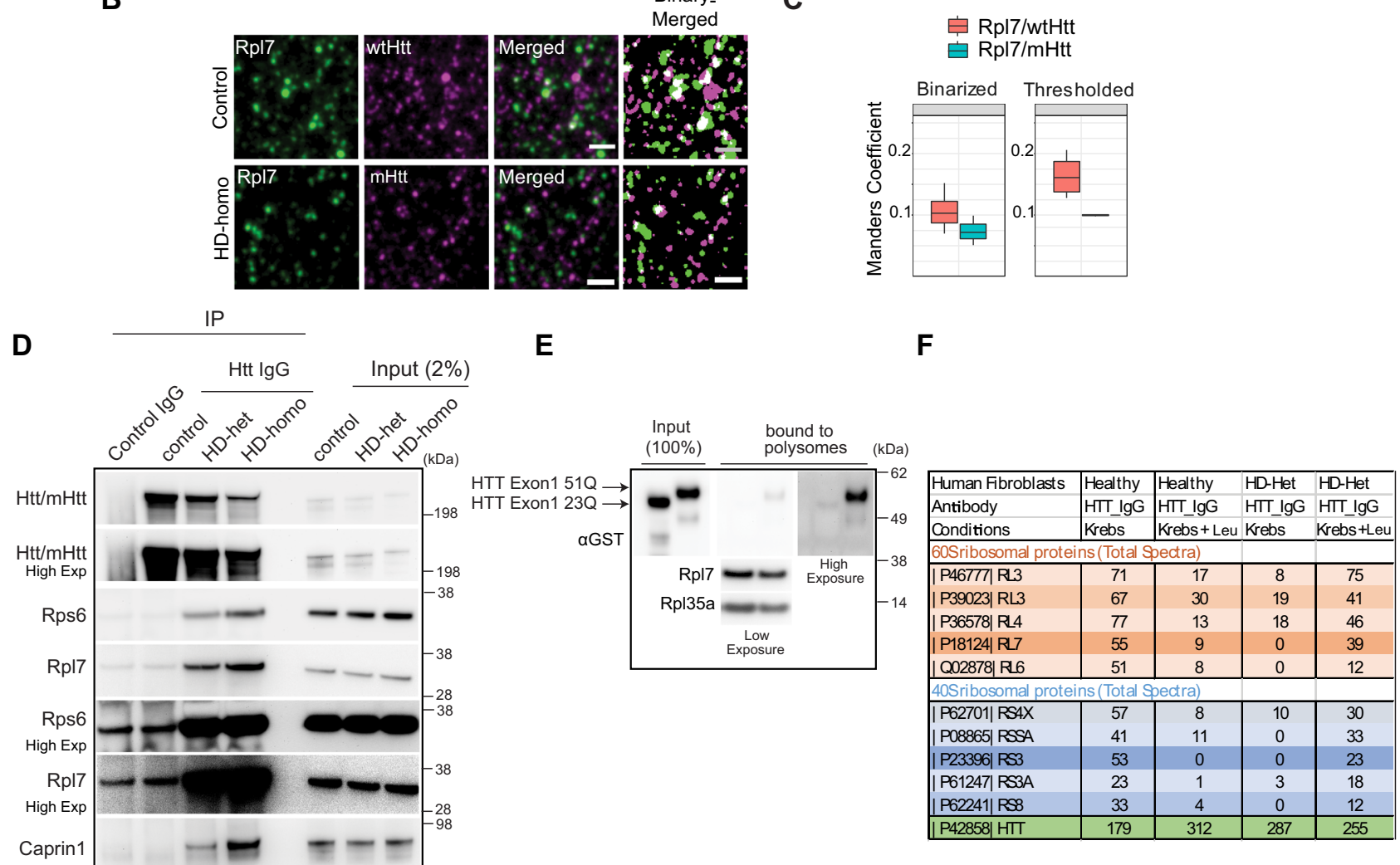

Because the data indicate ribosomes were stalled in HD cells, our goal was to identify mRNA targets with high RPF in HD. For this, we used Anota2Seq bioinformatics software ${ }^{97}$, which applies partial and random variance models to allow the analysis of differential RPF (a.k.a. translation efficiency) between control and HD cells and estimation of the changes within each RNA source (RPF or mRNA) ${ }^{98}$. The following six categories of RPF/mRNA groups showing differential ribosome occupancy between control, HD-het, and HD-homo, striatal cells, were expected in our analysis: (a) high RPF/similar mRNA ( $\uparrow R P F / \bullet m R N A),(b)$ similar RPF/low RNA ( $(\mathrm{RPF} / \downarrow \mathrm{mRNA})$, (c) low RPF/similar mRNA $(\downarrow R P F / \bullet m R N A)$, (d) similar RPF/high mRNA (•RPF/ $\uparrow \mathrm{mRNA})$, (e) high RPF/high mRNA ( $\uparrow P P F / \uparrow m R N A)$, and (f) low RPF/low mRNA ( $\downarrow R P F / \downarrow$ mRNA) (Supplementary Fig. S10A).

We first confirmed that the Anota2Seq algorithms were able to separate the ribosome occupancy of each category from HD-het and HD-homo cells versus controls (Fig. 7C and Supplementary Data 3). As shown in the scatterplot (Fig. 7D), we found that the 
Fig. 6 Huntingtin interacts with ribosomes. A Representative polysome profile and immunoblots with indicated proteins in the fractions from the gradients of control and HD-homo cells treated with vehicle or Harringtonine ( $2 \mu \mathrm{g} / \mathrm{ml}, 30 \mathrm{~min})(n=3$ independent experiments). B Representative images of STED microscopy on mouse striatal cells using antibodies against Rpl7 (green) and Htt (magenta) counterstained with the nuclear marker DAPI (see the full image in Supplementary Fig. S5) Scale bar $=500 \mathrm{~nm}, n=4$ for control cells, $n=3$ for HD-homo cells. C The Manders' colocalization coefficients were calculated for the ratio of FarRed-label colocalizing with Red-label, for both control and homo conditions, using background subtracted (thresholded) and binarized STED images from B. The central line details the median (50\%), whereas the upper and lower boundaries of the box (hinges) represent the first (25\%) and third (75\%) quartile of the data. The whiskers extend up to the largest and down to the smallest value, all of which were inside $1.5{ }^{\star}$ IQR the interquartile range, or the distance between the first and third quartiles, $n=4$ for control cells, $n=3$ for HD-homo cells. D Representative immunoblots showing co-immunoprecipitation of $\mathrm{wHtt} / \mathrm{mHtt}$ (MAB2166) with indicated proteins, and input, $n=4$ independent experiments. E Representative immunoblots on inputs and outputs of in vitro ribosome-binding assays using recombinant GST-exon 1 HTT $23 \mathrm{Q}$ and GST-exon 1 HTT 51Q proteins and isolated ribosomes from mouse $\mathrm{Htt}$-depleted striatal cells ( $n=3$ independent experiments, see Supplementary Fig. S6 for the experimental diagram and corresponding polysome profiles). F Proteomics analysis on samples prepared from immunoprecipitation experiments on human (healthy controls $17 \mathrm{Q}$ and HD patient 69Q-het) fibroblasts in Krebs or Krebs $+3 \mathrm{mM}$ Leu (four control IgG and four HTT IgG, $n=1$ per group).

36,411 genes included 3840 mRNA targets in the HD-homo cells and 6670 mRNA targets in the HD-het cells, with significantly changed ribosome occupancy (RPF/mRNA) compared to the controls $(P$ value $<0.05$ ) (Supplementary Data 4 and 5). This differential RPF change in HD could also be due to transcriptlevel changes consistent with the transcriptional role of $\mathrm{mHtt}{ }^{99}$. Gene ontology (GO), using the Ingenuity Pathway Analysis (IPA) for each category, showed that the genes belong to diverse signaling pathways, including IL-10 signaling, Alzheimer's disease signaling, AMPK signaling, cAMP signaling, Rho GTPase signaling, and the matrix metalloprotease, EIF2, and mTOR pathways (Supplementary Fig. S10B). Therefore, we were able to ensure our Ribo-Seq data to detect robust differences in the RPF in HD cells compared to the control.

We next sought to identify the overall ribosome pauses on mRNA transcripts in HD using PausePred software ${ }^{100}$. Linear regression analysis using the mean of triplicates allowed a determination of the number of cases with a $5^{\prime}$ ribosomal shift and a $3^{\prime}$ ribosomal shift in the HD and control cells. The HDhomo cells showed more genes with $5^{\prime}$ ribosome occupancy $\left(5^{\prime}=\right.$ $\left.790 ; 3^{\prime}=138\right)$, whereas HD-het cells showed more genes with $3^{\prime}$ occupancy $\left(5^{\prime}=74 ; 3^{\prime}=1685\right)$ (Fig. 8 A, Supplementary Data 6 and 7). For example, the mRNA of $B-m y c$, a brain-expressed myelocytomatosis oncogene ${ }^{101}$, showed high ribosome occupancy toward the $5^{\prime}$ end in HD-homo (Fig. 8B, arrow). By contrast, $m t-N d 4 I$ mRNA, a subunit of NADH dehydrogenase (ubiquinone), displayed high ribosome occupancy toward the $3^{\prime}$ end (Fig. 8B, arrowhead). These data indicate that the center of the ribosome density is significantly shifted on selected targets in HD cells compared to normal cells.

The PausePred software can also be used to analyze the global single-codon pauses ${ }^{100}$. However, although we observed numerous single-codon pauses between control and HD cells (Supplementary Fig. S11), the high level of variation within the replicates (Supplementary Fig. S12) precluded any comparison of pauses across groups. These variations within the replicates may also indicate that a ribosomal pause on a given codon is not a static but a dynamic event in striatal neuronal cells. We therefore selected the codons that showed HD-exclusive pauses compared to control cells. This approach identified $\sim 165$ targets in the HDhomo cells and $\sim 125$ targets in the HD-het cells that showed one or more codon-specific pauses (Supplementary Data 8 and 9). Most of the targets showed ribosome pauses toward the $5^{\prime}$ end as well as the $3^{\prime}$ end of the coding mRNA in HD cells compared to controls (Fig. 8C). Although we can draw no clear conclusion whether the observed pause signal was a result of pausing or simply due to differences in the transcript, we found that most of the single-codon paused transcripts $(\sim 130)$ were enriched in the top PS-bound mRNA list in PS-RRA-mRNA-Seq of the HDhomo cells (Fig. 8D) (Supplementary Data 10).
We next examined the ribosome profiles of some of the targets identified in both Ribo-Seq and PS-RRA-mRNA-Seq and their protein expressions (depending on the availability of antibodies). We combined the uploaded profiles, as a track hub in the University of California Santa Cruz (UCSC) Genome Browser 42, from the triplicate experiments and overlaid selected RPF (green) normalized to corresponding mRNA (orange). We also estimated the ribosome occupancy as the ratio between CDS RPF abundance and mRNA abundance and for the indicated gene (RPF/mRNA) from the raw read counts from the UCSC browser (Fig. 9A-F, bar graphs). For example, $M f s d 10$, an ion transporter, showed a single-codon pause at position 1673 (GAG) and enhanced RPF/mRNA reads in the HD-het and HD-homo cells (Fig. 9A, arrow). By contrast, Acan, a proteoglycan consisting of seventeen exons, showed more or less uniformly distributed ribosome occupancy in control and HD-het cells. Its single-codon pause was at 2515 (TGG), and its RPF was concentrated predominantly toward the $5^{\prime}$ of the mRNA transcript in HDhomo cells (Fig. 9B, arrow). Ppbp, platelet-derived growth factor, which belongs to the CXC chemokine family, consists of three exons and showed high RPF concentrated on exon 2 in HD-het and HD-homo compared to control (Fig. 9C, arrow). $M g p$, $\mathrm{N}$-methylpurine-DNA glycosylase, showed a single-codon pause at 100 (AGC) and high RPF reads in HD-het and HD-homo cells compared to control cells, with RPF tilted more toward $3^{\prime}$ in the HD-het cells (Fig. 9D, arrow). Phf11d, a protein containing a PHD (plant homeodomain) type zinc finger, has 11 exons and showed high RPF in HD-homo (18-fold) compared to control cells (Fig. 9E, arrow). mTOR, a widely studied kinase, shows a high RPF at the $5^{\prime}$ end of the mRNAs but it gradually tapered down along the 58 exons in all groups (Fig. 9F).

Therefore, RPF/mRNA analysis showed overall high RPF in Mfsd10, Ppbp, Mgp, and Phf11d targets in HD cells compared to control cells. Apart from Acan, the rest of the targets showed diminished protein levels by western blotting in $\mathrm{HD}$ cells compared to control, but the mTOR protein levels were not significantly altered (Fig. 9G). Thus, despite a high RPF density, certain selected targets showed diminished or unaltered protein levels in HD cells compared to control cells, suggesting a possible translational regulation including ribosome stalling and/or posttranslational mechanisms of protein stability in HD.

We have recently evaluated whether paused targets play any role in HD. We reported that cGAS, a DNA sensor ${ }^{102}$ (Fig. 8D, arrow), showed high ribosome occupancy at its exon 1 and a pause at 171 (CCG) and 172 (CGT) in HD cells ${ }^{103}$ and that the cGAS protein is highly upregulated in HD cells, HD mouse models, and human patient tissues. We also showed that cGAS promotes an inflammatory and autophagic response in HD cells $^{103}$. A full UCSC genome browser link for the global RPF averaged for all three replicates for control, HD-het, and HD- 
A

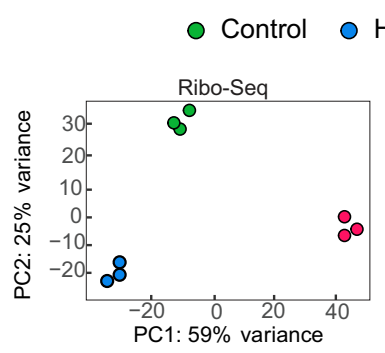

B
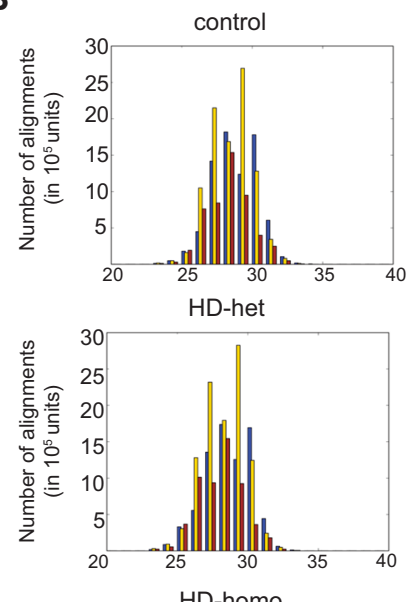

HD-homo

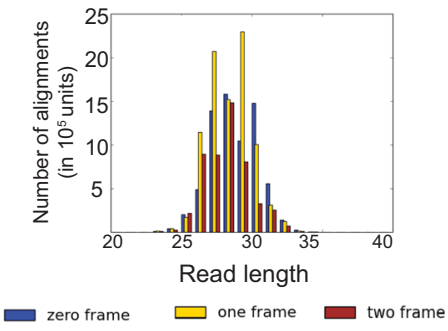

D

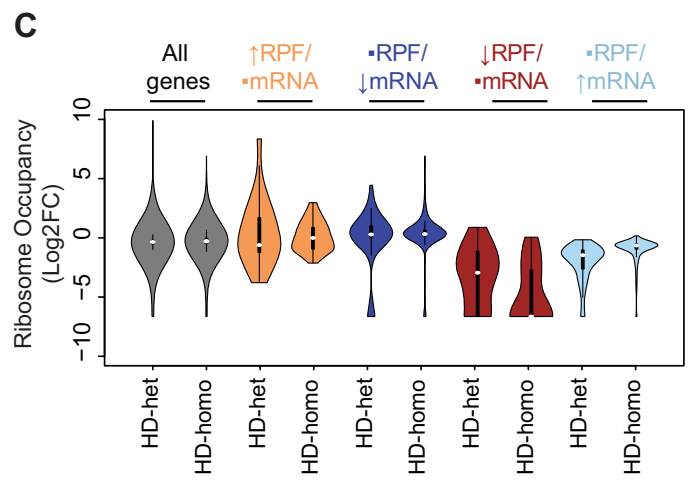

HD-Het vs. control
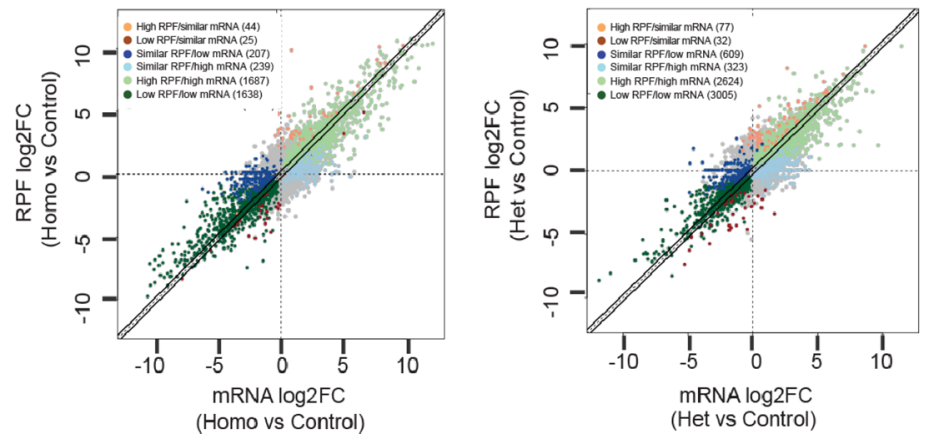

Fig. 7 Global ribosome profiling reveals diverse ribosome occupancy on mRNA transcripts in HD cells. A Principal component analysis using Ribo-Seq and RNA-Seq data obtained from control, HD-het, and HD-homo striatal cells. B Representative graphs showing triplet periodicity plots generated for protein-coding regions of Ribo-Seq data obtained from control, HD-het and HD-homo striatal cells. C Violin plots showing the distribution of ribosome occupancy changes (calculated by the number of Ribo-Seq reads divided by mRNA-Seq reads for each gene, Log2FC) in HD-homo and HD-het cells (compared to control cells). In the middle of each density curve is a small boxplot, with the rectangle showing the ends of the first and third quartiles and central dot the median ( $n=3$ independent experiments). D Scatter plots of expression changes of Ribo-Seq vs mRNA-Seq data in control, HD-het, and HDhomo striatal cells. Using Anota2seq, changes in Ribo-Seq are classified into six groups (see Supplementary Fig. S10A). The numbers of genes in each group are shown at the top left corner of each plot. The total number of genes: 36411 , absolute fold change $(F C)>2$, nominal $P<0.05$, and false discovery rate $(F D R)=0.15$. All statistical tests within the anota2seq package are two-tailed.

homo cells can be found at the UCSC genome browser (see "Data availability" for the link).

Thus, our Ribo-Seq analysis revealed robust differences in the RPF/mRNA, $5^{\prime}$, and $3^{\prime}$ distribution of ribosomes and single-codon pauses on selected mRNA transcripts. This study also provides a rich source of potential unknown targets for drug discovery in HD research.

\section{Discussion}

Despite many efforts, no effective therapies are yet available that are directed toward inhibiting the abnormal functions of $\mathrm{mHtt}$ in HD. Therefore, delineating the mechanisms become important for developing effective therapies against HD. Based on the present study findings, our model indicates that wtHtt physiologically inhibits protein synthesis by inhibiting the speed of ribosomal translocation. This function is exacerbated by $\mathrm{mHtt}$, which further impedes protein synthesis and aberrantly slows down ribosomal translocation (Fig. 9H). This model is supported by multiple pieces of evidence from the present study: (i) an enhanced level of polysome-bound mRNA transcripts but a diminished level of protein synthesis in HD cells, (ii) increased protein synthesis as well as increased speed of ribosome runoff by depletion of $\mathrm{mHtt}$, (iii) direct inhibition of protein synthesis in vitro by $\mathrm{mHtt}$, (iv) an association between $\mathrm{mHtt}$ and translating ribosomes, and (v) widespread alterations in the ribosome occupancy in HD cells compared to control cells. 
A

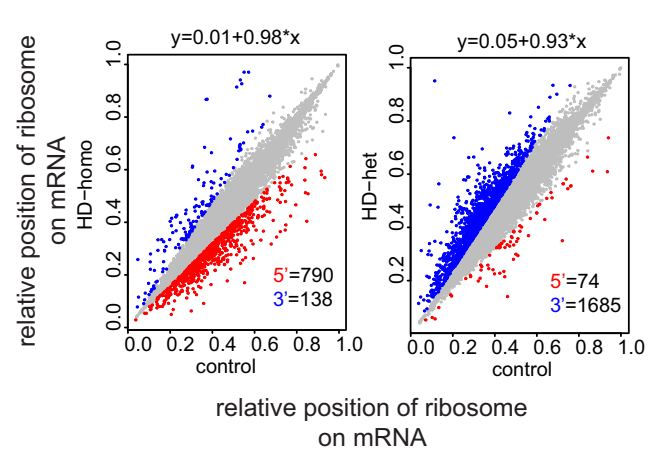

B

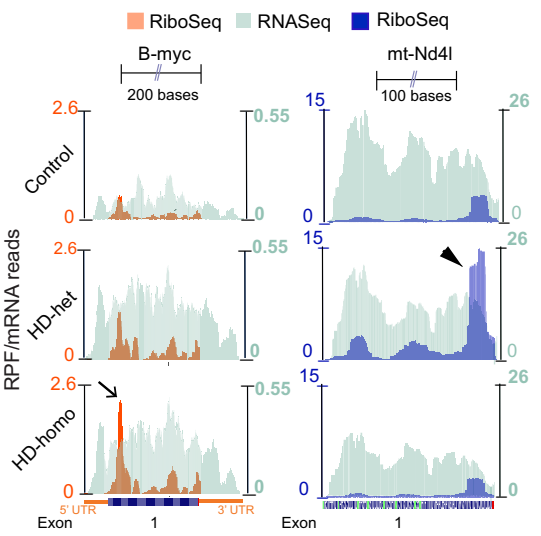

C

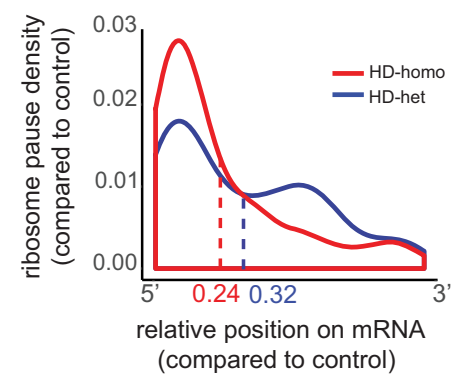

D
- down Single codon paused targets - up unaltered

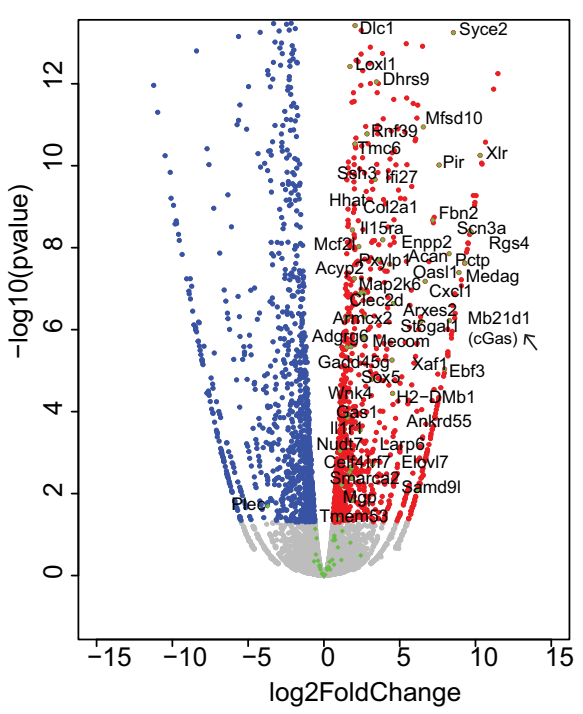

Fig. 8 Analysis of $\mathbf{5}^{\prime}$ - and $\mathbf{3}^{\prime}$-end ribosome occupancy and single-codon pauses in HD cells. A Each dot represents the mean center ribosome density score of the same transcript in HD cells vs control cells $(n=3)$. Red dots represent transcripts with higher $5^{\prime}$ ribosome occupancy in HD cells vs control cells. Blue dots represent transcripts with higher $3^{\prime}$ ribosome occupancy in HD cells vs controls. The axis indicates the relative position of the ribosome on the mRNA transcript. B Graphs showing the overlay of Ribo-Seq (RPF)/mRNA-Seq reads for B-myc and mt-ND4I, gene obtained from UCSC browser. C Pause density plot showing the distribution of common paused codons (found among three replicates of HD cells versus control cells) over their corresponding mRNAs. Numbers showed at the bottom represent the average of relative positions of paused codons in HD-homo (red) and HD-het (blue) cells. D Volcano plot from Fig. 4B representing changes in gene expression levels of ribosome-bound mRNAs in HD-homo cells (vs control cells) after ribosome run-off assay, showing single-codon paused targets (green). mRNA transcripts with absolute log2 fold change $>0.3$ and FDR-corrected $P$ value $<0.05$ are shown with red (up, increased polysome binding, $\log 2 \mathrm{FC}>1$ ), blue (down, decreased polysome binding, $\log 2 \mathrm{FC}<1$ ), gray (unaltered, no difference in polysome binding). Statistical testing was done using DESeq2 with a two-tailed Wald test and adjusted for multiple comparisons using the procedure of Benjamini-Hochberg.

Surprisingly, despite an approximately two-fold increase in the levels of Fmrp, a previously known regulator of ribosome stalling and mRNA translation ${ }^{18,104-107}$, depletion of Fmrp did not significantly affect ribosome stalling or protein synthesis in HD cells. Previous studies have shown a biochemical association of Fmrp and $\mathrm{Htt}$, as $\mathrm{Htt}$ mRNA is a target for Fmrp binding in the brain ${ }^{16}$, and Fmrp binds with $3^{\prime}$ UTR of $H t t$ mRNA ${ }^{108}$. A recent study showed that Fmrp deficiency leads to reduced $\mathrm{Htt}$ mRNA expression and that Htt mediates the Fmrp regulation of mitochondrial fusion and dendritic maturation ${ }^{109}$. Thus, $\mathrm{Htt}$ and Fmrp may act together in a cell-type-specific manner and have yet undiscovered biological functions in the brain. Although Fmrp upregulation did not affect translation in HD cultured striatal cells, we cannot rule out its role in HD pathogenesis. This notion is supported by evidence suggesting that deletion of Fmrp (dfmr1) suppresses the mHTT-mediated toxicity in the
Drosophila model of $\mathrm{HD}^{110}$. In the HD brain, hypothetically, Fmrp may regulate the translation of selected mRNA transcripts involved in synaptic functions ${ }^{104,111,112}$. In addition, Fmrp upregulation may impact noncanonical functions, such as autophagy regulation in $\mathrm{HD}^{113,114}$. Thus, our study demonstrates a previously unknown link for mHtt and Fmrp and its relevance to HD pathogenesis requires further studies.

Our results demonstrating a role for $\mathrm{Htt}$ in protein synthesis in HD is consistent with the findings of previous studies ${ }^{73,75-78}$. These earlier studies showed that full-length wtHtt or $\mathrm{mHtt}$ interacted with ribosomal proteins in the brain and inhibited capdependent translation of a reporter mRNA in Hela cells ${ }^{75}$. Similarly, the expression of the fragment of the first 17 amino acids of Htt fused to a poly (Q) tract of 103 (Htt103Q) in yeast cells and Drosophila cells diminished the expression of genes involved in rRNA metabolism and ribosome biogenesis, while 


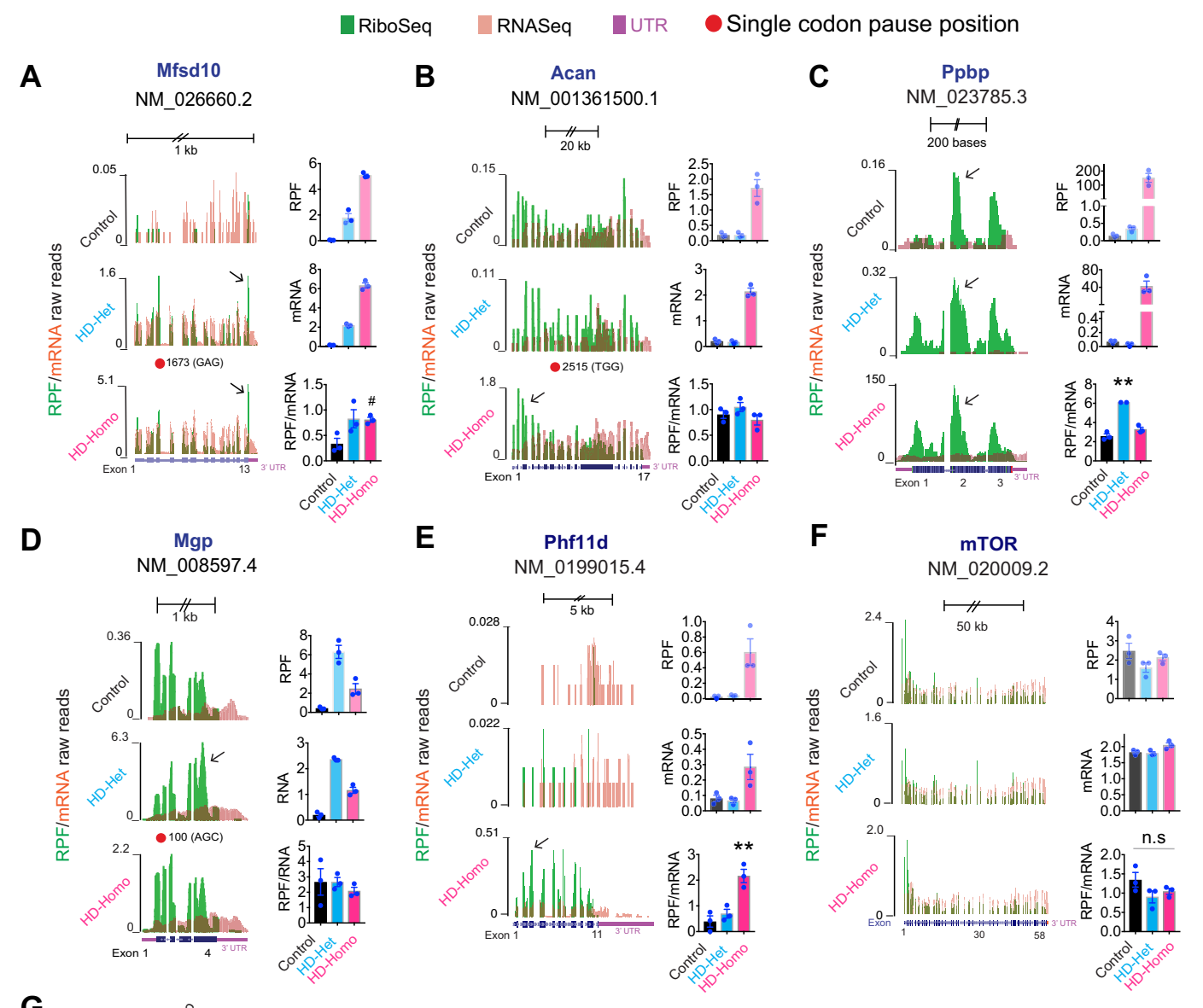

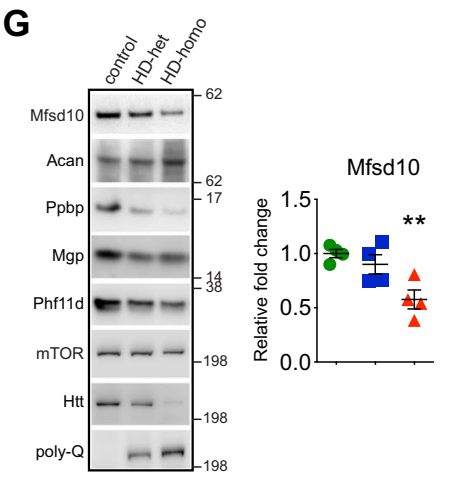

H

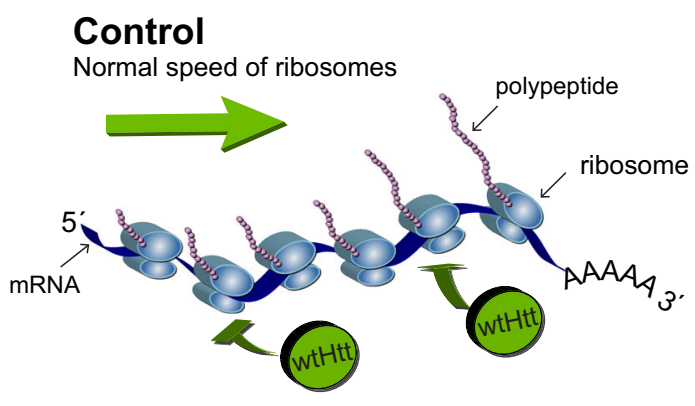

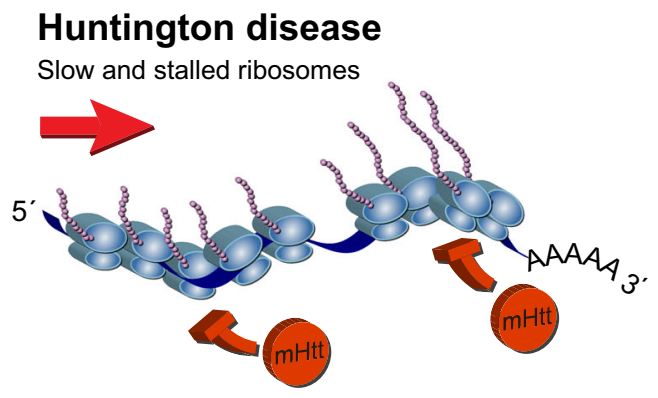

also suppressing protein synthesis ${ }^{73,76}$. Protein/gene expression profiling has revealed diminished protein levels, altered expression of genes encoding ribosomal proteins, and RNA processing proteins in various $\mathrm{HD}$ models $\mathrm{s}^{51,70,71,74,115,116}$, indicating a strong translational role for mHtt. But the mechanisms of how mHtt might promote translational abnormalities were not revealed by these previous works.
Our data show both wtHtt and mHtt appear to act as inhibitors of translation elongation, we predict that they can elicit gain or loss of function activities toward protein synthesis, depending upon how much (levels) and what (with or without $\mathrm{mHtt}$ ) is present on the ribosomes as well as where $\mathrm{Htt} / \mathrm{mHtt}$ is present (localization). In support of this notion, our super-resolution Ribo-Seq data revealed markedly different RPF/mRNA profiles 
Fig. 9 Ribosome stalling was confirmed in several genes by measuring protein levels. A-F Representative graphs showing the overlay of Ribo-Seq (RPF)/ mRNA-Seq reads for indicated genes obtained from UCSC browser. Bar graphs indicate RPF abundance, mRNA abundance, and ribosome occupancy as the ratio between CDS of RPF and mRNA for the indicated gene (RPF/mRNA) from the raw read counts from the UCSC browser. Data mean \pm SEM ( $n=3$ independent experiments, ${ }^{\#} P<0.05$ by two-tailed Student's $t$ test, ${ }^{\star \star} P<0.01$ by one-way ANOVA followed by Tukey's multiple comparison test. n.s. not significant. G Representative immunoblots showing the protein expression levels of indicated genes in A-F and the corresponding quantifications. Data mean \pm SEM, $n=4$ independent experiments, ${ }^{\star} P<0.05$ and ${ }^{\star \star} P<0.01$ by one-way ANOVA followed by Tukey's multiple comparison tests. Exact $P$ values are reported in the Source Data file. Source data are provided as a Source Data file. H Model showing wtHtt bind to ribosomes and physiologically inhibits the translocation of ribosomes on mRNA, a normal function that is further enhanced by mHtt leading to slower movement and stalling of ribosomes. Note stoichiometry of wtHtt/mHtt binding to ribosomes is currently unknown.

between HD-homo cells and the control and between HD-het and the control cells (Fig. 7D). Previously, we showed that mHtt activates amino acid-induced Rheb-mTORC1 signaling, which promotes the initiation of mRNAs containing the $5^{\prime}$-terminal oligopyrimidine ( $5^{\prime}$ TOP) motif ${ }^{117,118}$. We also showed Rheb can inhibit protein synthesis by activating the PERK-eIF2 $\alpha$ signaling cascade $^{119}$. Interestingly, a recent study demonstrated enhanced protein synthesis in the brains of R6/1 transgenic and Hdh Q7/Q111 knock-in mice, while Q175FDN mice showed diminished levels of soluble proteins ${ }^{77,120}$. Thus, mHtt may modulate protein synthesis depending upon the interacting partners, nutritional status of the cells, and the changes in the intact brain environment in vivo.

Previous elegant studies have suggested multiple players in the regulation of ribosome stalling, including secondary RNA structures, $3^{\prime}$ UTR, codon usage, or the availability of charged tRNAs, ribosomal-binding proteins, and/or nascent polypeptide chains, which may all contribute to ribosomal pauses ${ }^{1-4}$. Whether similar mechanisms operate in striatal neuronal cells, and whether $\mathrm{mHtt}$ recruits one or more of these players to stall ribosomes, remains unknown. Htt consists of 28-32 HEAT [Huntingtin, elongation factor 3 (eEF3) 1, protein phosphatase 2A (PP2A) 2, and the yeast $\mathrm{PI3}$-kinase TOR1] repeats that span the entire protein. Many translation regulators, such as eEF3, eIF4Gs, p97DAP5, GCN1, and mTOR, contain HEAT repeats. These repeats are tandem repeats of an alpha-helical hairpin that form a superhelical structure with hydrophobic cores; this structure is predicted to interact with other proteins and/or nucleic acids ${ }^{121,122}$. Structural analysis has shown that yeast eEF3 HEAT (13) repeats interact with rRNA and the ribosomal proteins of the small ribosomal subunit, and this is proposed to play a role in the translocation of aminoacyl-tRNA from the A site to the P site on the ribosome ${ }^{123-125}$. Similarly, yeast eIF4G HEAT (four) repeats have been shown to interact with eIF4A and to stimulate its ATPase activity to facilitate $43 \mathrm{~S}$ preinitiation complex recruitment and movement along the mRNA in a $5^{\prime}$ to $3^{\prime}$ direction ${ }^{126}$. Thus, mHtt may interact with ribosomes via HEAT repeats to modulate ribosome stalling.

Short fragments and aggregated forms of Htt may also differentially influence ribosome stalling. Htt is proteolytically cleaved by several proteases, resulting in smaller $\mathrm{N}$-terminal poly- $\mathrm{Q}$ containing exon 1 and non-poly-Q Htt C-terminal fragments, which are considered important for disease pathogenesis $54,127,128$. Although we found FL-mHtt present on the polysomes and interacts with ribosomal proteins, previous work has shown that exon 1 aggregates could also be associated with ribosomes ${ }^{129,130}$. Therefore, different Htt fragments (e.g., poly-Q exon 1 and HEAT repeat domains) and aggregated forms ${ }^{54,63,131}$ may differentially bind to the translating ribosomes. For example, $\mathrm{mHtt}$ aggregates are sequestered by the cytoplasmic polyadenylation element-binding protein/Orb2 $2^{76}$, a translational regulator ${ }^{132,133}$, whose mRNA shows an enhanced ribosome occupancy in HD (see UCSC browser link), indicating Orb2 may be involved in ribosome stalling in HD. Notably, the association of protein aggregates with ribosomes, as found with various neurodegenerative disease-linked proteins, may have a considerable impact on the mRNA translational machinery ${ }^{134-136}$. Further identifying the nature and stoichiometry of Htt fragment binding to the ribosomes and its binding partners may yield molecular insights into dynamic protein synthesis regulation in HD cells.

One question that remains is whether or how mHtt-mediated ribosome stalling influences striatal-specific damage in $\mathrm{HD}^{137,138}$. We previously showed that striatal-enriched Rhes promotes HD toxicity in cell and animal models ${ }^{139,140}$ by enhancing the SUMOylation of $\mathrm{mHtt}$ and increasing its solubility ${ }^{139,141}$. Several independent studies support a toxic role for Rhes in various HD models ${ }^{139,140,142-148}$. Recently, we demonstrated that Rhes promotes cell-to-cell transport of $\mathrm{mHtt}$ via tunneling nanotube (TNT)-like protrusions ${ }^{149}$. Rhes also activates mTORC1 signaling ${ }^{150}$, a known mediator of mRNA translation 151,152 , but how this may influence ribosome stalling in HD remains to be determined. We propose that a Rhesmediated enhancement of mHtt solubility may further worsen ribosome stalling in the striatum and interfere with Rhesmediated intercellular communication via the TNT-like protrusions; other cellular and inflammatory processes may also contribute to ribosome stalling and selective neurodegeneration in $\mathrm{HD}^{68,103,137,138,153}$.

Taken together, our findings indicate that mHtt suppresses protein synthesis via ribosome stalling potentially during translation elongation. This altered function may mediate progressive and widespread development of HD-related behavioral and pathological symptoms. Developing drugs that interfere with mHtt-mediated mechanisms of ribosome stalling may prevent or slow down the progression of $\mathrm{HD}$.

\section{Methods}

Chemicals and cell culture. Chemicals and reagents were mainly purchased from Sigma. Mouse striatal cells (STHdh) expressing knock-in wild-type HTT ${ }^{\text {exonl } 1}$ with 7 glutamine $(\mathrm{Q})$ repeats (control; STHdh ${ }^{Q 7 / Q 7}$ ) or expressing knock-in mutant human HTT ${ }^{\text {exon1 }}$ with 111 glutamine repeats (HD-het; STHdhQ7/Q111, and HDhomo; STHdh $\left.h^{Q 111 / Q 111}\right)^{80}$ were purchased from Coriell Institute for Medical Research (Camden, NJ, USA) and cultured in Dulbecco's modified Eagle's medium, high glucose, GlutaMAX supplement (DMEM) (Thermo Fisher Scientific) supplemented with 10\% fetal bovine serum (FBS) (Thermo Fisher Scientific), 1\% penicillin-streptomycin $5 \% \mathrm{CO}_{2}$, at $33^{\circ} \mathrm{C}$, as described before ${ }^{118}$. HD patientderived fibroblast cell lines GM04281 (wild-type HTT allele/17 CAG repeats, mutant HTT allele/69 CAG repeats) and normal human fibroblast cell line GM07492 were obtained from Coriell Institute for Medical Research (Camden, NJ, USA). Cells were maintained at $37^{\circ} \mathrm{C}$ and $5 \% \mathrm{CO}_{2}$ in DMEM, high glucose, GlutaMAX supplement supplemented with $10 \%$ FBS, $1 \%$ penicillin-streptomycin, and $1 \%$ MEM nonessential amino acids (Thermo Fisher Scientific).

Antibodies. The following commercial antibodies were used: Huntingtin (MAB2166, 1:3000) and puromycin (MABE343, 1:10,000) antibodies were obtained from, Millipore-Sigma. Anti-polyglutamine (poly-Q) antibody (P1874, 1:5000) was from Sigma. Actin (sc47778, 1:20,000) and GST-horseradish peroxidase (HRP, sc138 HRP, 1:10,000) antibodies were from Santa Cruz Biotechnology. RPL7 (IHC-00455, 1:10,000), RPL35A (A305-106A, 1:10,000) and Caprin1 (A303881A, 1:1000) from Bethyl Laboratories. mTOR (2972, 1:3000), FMRP (4317, $1: 1500)$, and S6 $(2217,1: 10,000)$, and normal mouse IgG $(5415,1: 2500)$ were from Cell Signaling Technology. Mfsd (10 11518-1-527 AP, 1:1000), Acan (13880-1-AP, 
1:1000), Ppbp (13313-1-AP, 1:1000), Mgp (10734-1-AP, 1:1000), and Phf11d (10898-1-AP, 1:1000) were from Proteintech. HRP-conjugated secondary antibodies were from Jackson ImmunoResearch Inc. HRP-conjugated secondary antibodies (115-035-146 (goat anti-mouse), 1:10,000; or 111-035-144 (goat antirabbit), 1:10,000) were from Jackson ImmunoResearch Inc. For Immunostaining Huntingtin (1:100, MAB2166), Rpl7 (1:50; IHC-00455) were used. Secondary antibodies for STED microscopy were anti-mouse STAR 635p (1:400) and antirabbit Alexa 594 (1:400) that were self-coupled in-house and the company that produced them is Abberior, Göttingen, Germany.

Deletion of $\boldsymbol{H d h}$ (Htt) and Fmr1 (Fmrp) genes using CRISPR/Cas9. GFP expressing CRISPR/Cas9 knockout plasmids for mouse Htt (sc-420825) and Fmrl (sc-420392) or CRISPR/Cas9 control plasmid (sc-418922) were purchased from Santa Cruz Biotechnology. Mouse striatal cells were transfected with knockout plasmids by PolyFect (Qiagen) following recommendations by the company. The transfected cells were harvested $48 \mathrm{~h}$ later, washed, and resuspended in the sorting buffer (containing $1 \times$ phosphate-buffered saline $\left(\mathrm{Ca} / \mathrm{Mg}^{++}\right.$free), $2.5 \mathrm{mM}$ EDTA, $25 \mathrm{mM}$ HEPES $\mathrm{pH}$ 7.0, $1 \%$ fetal bovine serum, and $10 \mathrm{unit} / \mathrm{ml}$ DNase1). The GFP expressing cells were sorted using a BD biosciences Aria FACs machine. The sorted cells were plated and maintained in DMEM high glucose containing 10\% FBS at $33^{\circ} \mathrm{C}$

Immunostaining of the cells and STED image acquisition. Mouse striatal cells were plated in 12-well plates containing glass coverslips. The day after, the cells were washed with PBS and fixed using 4\% PFA in PBS, then permeabilized in $0.1 \%$ Triton X-100 in PBS and blocked using 5\% normal donkey serum/ 1\% BSA/ 0.1\% Tween in PBS. The cells were incubated with primary antibodies (Htt 1:100, MAB2166, Rpl7 1:50; IHC-00455) in blocking buffer at $4{ }^{\circ} \mathrm{C}$ overnight. The day after, the cells were washed and incubated with secondary antibodies and DAPI in $1 \%$ BSA/ 0.1\% Tween in PBS for $1 \mathrm{~h}$ at room temperature. The stimulated emission depletion (STED) microscopy imaging was performed using a multicolor ExpertLine STED nanoscope (Abberior Instruments $\mathrm{GmbH}$ ), using the 775-nm pulsed STED laser in combination with the 561-nm and 640-nm pulsed excitation lasers, as well as the $405-\mathrm{nm}$ excitation for diffraction-limited imaging of DAPI. All images were recorded simultaneously with diffraction-limited (i.e., confocal) and with 2D-STED enhanced resolution, recording each color channel and resolution in a line-interleaved manner. Pixel sizes $(x, y)$ were $20-\mathrm{nm} \times 20$ - $\mathrm{nm}$ for both STED and confocal images, with typical pixel dwell times of $10 \mu$ s for confocal and $30-45$ $\mu$ s for STED images. The images were recorded with a $\times 100$ oil immersion objective lens (NA 1.4), using the QUAD beam scanner, utilizing the Imspector software package (Max-Planck Innovation).

Image analysis. For the colocalization analysis, raw STED images from Imspector were imported into FIJI and were processed as follows. First, raw images were gently smoothed with a one-pixel Gaussian filter. Next, an appropriate background level was determined individually for each image, striking a careful balance between being able to distinguish individual clusters in proximity without losing any of the dimmer features. This background value was then subtracted from the images. For some parts of the analysis, the images were then binarized. Regions coinciding with the cell nucleus were excluded from the colocalization analysis, as were smaller regions coinciding with any obvious staining artifacts. The colocalization analysis itself was performed using the ImageJ plugin JACoP, utilizing both the pixel-based Manders coefficient analysis and the object-based methods. The data is presented as boxplots that were generated using R Statistics (www.r-project.org).

Puromycin metabolic labeling and immunoblotting. Mouse striatal cells were plated at a confluency of about $60-70 \%$. The day after the cells were incubated with puromycin $\left(20 \mu \mathrm{M}\right.$ final concentration) for $5 \mathrm{~min}$, as described ${ }^{81}$. Then cells were rinsed with cold PBS and immediately were lysed in RIPA buffer containing protease inhibitors. Equal proteins were used to run western blotting experiments. The puromycin incorporation was normalized to the ponceau S staining.

Immunoprecipitation in striatal cells. Control, HD-Het, and HD-Homo striatal cells $\left(2 \times 10^{6}\right)$ were plated in 10 -cm dishes, and next day were lysed in immunoprecipitation (IP) buffer (15 mM HEPES (pH 7.3), $7.5 \mathrm{mM} \mathrm{MgCl} 2,100 \mathrm{mM} \mathrm{KCl}$, $1.0 \%$ Triton X-100, $1 \mathrm{mM}$ dithiothreitol (DTT), EDTA-free protease inhibitor

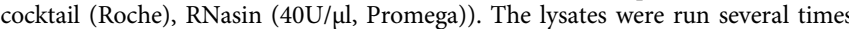
through a 26-gauge needle in IP buffer and incubated on ice for $15 \mathrm{~min}$ and centrifuged $20,000 \times g$ for $15 \mathrm{~min}$. Protein estimation in the lysate supernatant was done using a bicinchoninic acid (BCA) method, a concentration $(1 \mathrm{mg} / \mathrm{ml})$ of protein lysates was precleared with $40 \mu \mathrm{l}$ of protein $\mathrm{A} / \mathrm{G}$ beads for $1 \mathrm{~h}$, the supernatant was incubated for $1 \mathrm{~h}$ at $4{ }^{\circ} \mathrm{C}$ in HTT IgG (MAB2166) or control IgG, and then $60 \mu \mathrm{l}$ protein $\mathrm{A} / \mathrm{G}$ beads were added and incubated overnight at $4^{\circ} \mathrm{C}$. After 12 $h$, the beads were washed five times with IP buffer (without RNasin/protease inhibitor), and the protein samples were eluted with $30 \mu \mathrm{l}$ of $2 \times$ lithium dodecyl sulfate (LDS) containing $+1.5 \% \beta$-mercaptoethanol, separated on NuPAGE $4-12 \%$ Bis-Tris gel (Thermo Fisher Scientific), transferred to polyvinylidene difluoride membranes, and probed with the indicated antibodies. HRP-conjugated secondary antibodies (Jackson ImmunoResearch Inc.) were probed to detect bound primary
IgG with a chemiluminescence imager (Alpha Innotech) using enhanced chemiluminescence from WesternBright Quantum (Advansta).

Immunoprecipitation in human fibroblasts and LC-MS/MS. Human healthy and HD fibroblasts were plated in $10-\mathrm{cm}$ dishes and the next day the medium was changed to Krebs buffer medium (20 mM HEPES pH 7.4, glucose ( $4.5 \mathrm{~g} /$ liter), 118 $\mathrm{mM} \mathrm{NaCl}, 4.6 \mathrm{mM} \mathrm{KCl}, 1 \mathrm{mM} \mathrm{MgCl} 26 \mathrm{H}_{2} \mathrm{O}, 12 \mathrm{mM} \mathrm{NaHCO} 3,0.5 \mathrm{mM} \mathrm{CaCl}$, $0.2 \%(\mathrm{w} / \mathrm{v})$ bovine serum albumin (BSA)) devoid of serum and amino acids for $1 \mathrm{~h}$ to simulate full starvation conditions. For the stimulation conditions, cells were stimulated for $15 \mathrm{~min}$ with $3 \mathrm{mM}$ L-Leucine (Leu). Cells were lysed and proceeded for IP for HTT as mentioned above for the striatal cells using HTT IgG (MAB2166) and control IgG. After running the IP samples in electrophoresis, the samples were subjected to IP-LC-MS/MS as described previously ${ }^{154}$ for the analysis of HTT interactors

Eight protein samples named $\mathrm{H} 1, \mathrm{H} 2, \mathrm{H} 3, \mathrm{H} 4, \mathrm{H} 5, \mathrm{H} 6, \mathrm{H} 7$, and $\mathrm{H} 8$ (details in Supplementary Table 1) and $4 \mathrm{mg}$ of BSA control were subjected in parallel to SDSPAGE at $120 \mathrm{~V}$ for $12 \mathrm{~min}$. The gel was Coomassie-stained for $1 \mathrm{~h}$ at room temperature with shaking, followed by de-staining in water overnight. The gel bands were cut, in-gel treated with $25 \mathrm{mM}$ DTT followed by $55 \mathrm{mM}$ iodoacetamide, and subjected to trypsin digestion with ProteaseMax Surfactant Trypsin Enhancer for $1 \mathrm{~h}$ at $50^{\circ} \mathrm{C}$. The peptide pools were acidified and desalted through Zip-Tip $\mu \mathrm{C} 18$ tip columns. Prior to mass spectrometry analysis, the samples were reconstructed in $5 \mu \mathrm{l}$ of $0.1 \%$ formic acid and $5 \mu \mathrm{l}$ were loaded into the system. Each sample was analyzed by an Orbitrap Fusion Tribrid Mass Spectrometer (Thermo Fisher Scientific) coupled to an EASY-nLC 1000 system. Peptides were online eluted on an analytical RP column $(0.075 \times 150 \mathrm{~mm}$ Acclaim PepMap RLSC nano Viper, Thermo Fisher Scientific), operating at $300 \mathrm{nl} / \mathrm{min}$ using the following gradient: $5-25 \% \mathrm{~B}$ for 90 mins, $25-44 \%$ B for $30 \mathrm{~min}, 44-80 \%$ B in $10 \mathrm{~s}, 80 \%$ for $5 \mathrm{~min}, 80-5 \%$ B in $10 \mathrm{~s}$ and $5 \%$ B for $40 \mathrm{~min}$ (solvent A: $0.1 \%$ formic acid (v/v); solvent B: $0.1 \%$ formic acid $(\mathrm{v} / \mathrm{v}), 80 \% \mathrm{CH}_{3} \mathrm{CN}(\mathrm{v} / \mathrm{v})$ (Fisher Scientific)). The Orbitrap Fusion was operated in a data-dependent MS/MS mode using top speed precursor selection detected in a survey scan from 380 to 1400 mass/charge ratio $(\mathrm{m} / \mathrm{z})$ performed at $120 \mathrm{~K}$ resolution. Tandem MS was performed by higher-energy collisional dissociation fragmentation with a normalized collision energy of $30.0 \%$. Protein identification was carried out using Sequest algorithms (Proteome Discoverer v1.4, Thermo Scientific), allowing oxidation (Met) and deamination (Q) as variable modifications. Other settings included carbamidomethylation of Cys as a fixed modification, three missed cleavages, and mass tolerance of $10 \mathrm{ppm}$ and $0.02 \mathrm{Da}$ for precursor and fragment ions, respectively. MS/MS raw files were searched against a Uniprot human database. The FDRs of peptide identifications were calculated from the search results against a reverse sequence database; $1 \%$ FDR, was used as a criterion for peptide identification (the list of peptide identification is presented in data files Supplementary Data 2). Scaffold (version Scaffold_4.8.8, Proteome Software Inc., Portland, OR) was used to validate MS/MS-based peptide and protein identifications. The complete dataset from the analysis of the interactors (raw files, identification data, and data analysis files) can be obtained via ProteomeXchange with identifier PXD017115 at http://www.proteomexchange.org/.

Ribosome isolation and in vitro binding assay. For each assay, four $15-\mathrm{cm}$ plates of mouse striatal cells were used. Briefly, the cells were incubated with $100 \mu \mathrm{g} / \mathrm{ml}$ cycloheximide (CHX) for around $10 \mathrm{~min}$ at $37^{\circ} \mathrm{C}$, then harvested, spin down, and washed once with cold PBS containing CHX. The cells were lysed in the lysis buffer containing $20 \mathrm{mM}$ HEPES $\mathrm{pH} 7.3,150 \mathrm{mM} \mathrm{KCl}, 10 \mathrm{mM} \mathrm{MgCl}, 2 \mathrm{mM}$ DTT, $100 \mu \mathrm{g} / \mathrm{ml} \mathrm{CHX}, 0.5 \% \mathrm{v} / \mathrm{v}$ Triton X-100, $20 \mathrm{U} / \mathrm{ml}$ RNasin and EDTA-free protease inhibitor cocktail (Roche). The cell lysates were loaded on $10-50 \%$ sucrose gradients and centrifuged at $280,000 \times g$ (SW41Ti rotor) at $4{ }^{\circ} \mathrm{C}$ for $2 \mathrm{~h}$. Gradients were fractionated using a gradient fractionator and UA-6 detector, 254-nm filter (ISCO/ BRANDEL). The fractions containing monosome and polysomes were collected and transferred to a $50-\mathrm{mL}$ centrifuge tube and were diluted using isolation buffer containing $20 \mathrm{mM}$ HEPES $\mathrm{pH} 7.3,150 \mathrm{mM} \mathrm{KCl}, 10 \mathrm{mM} \mathrm{MgCl}, 2 \mathrm{mM}$ DTT, $100 \mu \mathrm{g} / \mathrm{ml}$ CHX (at least one in three for the monosome fractions and one in five for the polysome fractions). The diluted fractions were put on top of $1 \mathrm{M}$ sucrose cushion (made in isolation buffer) and centrifuged at $180,000 \times g$ (SW32Ti rotor) at $4{ }^{\circ} \mathrm{C}$ overnight. The pellets were rinsed gently with isolation buffer, then incubated with $50 \mu \mathrm{l}$ of ribosome isolation buffer, and stored on ice for $1 \mathrm{~h}$ to allow the resuspension of the isolated ribosomes. Isolated ribosomes $(50 \mathrm{nM}$ final concentration) were incubated with recombinant HTT exon 1 proteins $(500 \mathrm{nM}$ final concentration) in an isolation buffer for $10 \mathrm{~min}$ at room temperature. The samples were loaded on top of $10-50 \%$ sucrose gradients and centrifuged at $280,000 \times g$ (SW41Ti rotor) at $4{ }^{\circ} \mathrm{C}$ for $2 \mathrm{~h}$. The fractions containing monosomes were collected. Protein was precipitated and used to run western blotting assays. GST-HTT protein was produced in bacteria as described before ${ }^{139}$.

In vitro translation assay. Recombinant human HTT proteins were purchased from Coriell life sciences (HTT-Q23, 1-3144, TEV, FLAG C-TE; \# CH02228, HTT$\mathrm{Q} 48,1-3144, \mathrm{TEV}, \mathrm{FLAG}$ C-TE, \#CH02230). In vitro translation assays (IVTs) were performed using Flexi ${ }^{\oplus}$ Rabbit Reticulocyte Lysate System (Promega \#L4540) following the manufacturer's recommendations. Briefly, firefly luciferase mRNA (included in the kit) was used to measure translational regulation by HTT proteins 
comparing to BSA (as the control). Recombinant HTT proteins $(1 \mathrm{mg} / \mathrm{ml}$ ) or BSA $(1 \mathrm{mg} / \mathrm{ml})$ in $10 \mathrm{mM}$ Tris $\mathrm{pH} 8.0,1 \mathrm{mM}$ EDTA, were further dissolved in Tris buffer (50 mM Tris- $\mathrm{HCl} \mathrm{pH} \mathrm{7.4,} 500 \mathrm{mM} \mathrm{NaCl}, 10 \%$ glycerol, $0.1 \%$ CHAPS, and 1 mM EDTA). In total, $1 \mu \mathrm{l}$ of Q23 or Q48 or BSA containing desired concentrations were added to $25 \mu \mathrm{l}$ or $50 \mu \mathrm{l}$ rabbit reticulocyte IVT containing luciferase mRNA for $90 \mathrm{~min}$ at $30^{\circ} \mathrm{C}$ (IVT mixture). In control reactions, Q48 was added after $90 \mathrm{~min}$ of IVT for $5 \mathrm{~min}$. In all, $2 \mu \mathrm{l}$ of IVT mixture was added to $25 \mu \mathrm{l}$ of luciferase assay reagent, and luminescence activities were measured in each well every $30 \mathrm{~s}$ over a period of $1 \mathrm{~h}$ with 500 -ms integration time (data is presented for every 5 min) using a FlexStation3 plate reader (Molecular Devices). We avoided repeated freezing and thawing of recombinant HTT proteins as it drastically affected the activity in the IVT assay.

Ribosome run-off assay. Mouse striatal cells were plated at $60-70 \%$ confluency, on the next day were incubated with vehicle (DMSO) or harringtonine $(2 \mu \mathrm{g} / \mathrm{ml}$ final concentration) for indicated timepoints or puromycin $(100 \mu \mathrm{g} / \mathrm{ml})$ for $20 \mathrm{~min}$ at $37^{\circ} \mathrm{C}$. The cells were immediately incubated with $\mathrm{CHX}(100 \mu \mathrm{g} / \mathrm{ml})$ for $10 \mathrm{~min}$ and then scraped. Polysome profiles for each sample were collected and area under the curve for PS and 80S (MS) peaks in control and HD-homo cells, using PeakChart (v. 2.08, BRANDEL), and expressed as a ratio of PS/MS (Supplementary Fig. S1).

Postmortem HD brain samples. Postmortem frozen human brain tissue (Caudate nucleus) samples of HD-affected patients and normal donor controls used (Supplementary Table 2) in this study were obtained from Human Brain and Spinal Fluid Resource Center, VA West Los Angeles Healthcare Center, 11301 Wilshire Blvd. Los Angeles, CA 90073, which is supported in part by the National Institutes of Health (NIH) Neurobiobank (HHSN-271-201300029C) and the US Department of Veterans Affairs with informed consent from the donors. Human tissue collected from the NIH NeuroBioBank was overseen by institutional review board PCC \#: 2015-060672, VA Project \#: 0002 and were analyzed under ethical and safety guidelines approved by the Scripps Research Institute and its Institutional Review Board.

Western blot analysis. The cells were lysed in the lysis buffer containing $20 \mathrm{mM}$ HEPES pH 7.3, $150 \mathrm{mM} \mathrm{KCl,} 10 \mathrm{mM} \mathrm{MgCl} 2,2 \mathrm{mM}$ DTT, $100 \mu \mathrm{g} / \mathrm{ml} \mathrm{CHX,} \mathrm{0.5 \%} \mathrm{v/}$ v Triton X-100, $20 \mathrm{U} / \mathrm{ml}$ RNasin, and EDTA-free protease inhibitor cocktail (Roche) and an RNA concentration A260 reading of 10 OD, loaded on a $30-50 \%$ sucrose gradient. Individual fractions $(250 \mu \mathrm{l})$ were collected, the protein was precipitated using the methanol/chloroform method, and loaded for western blots analysis using antibodies to detect indicated endogenous protein. To examine Htt interaction with ribosomes HD-het cells were treated with vehicle (HEPES buffer) or puromycin $(100 \mu \mathrm{g} / \mathrm{ml})$ for $30 \mathrm{~min}$ at $37^{\circ} \mathrm{C}$ followed by lysis and sucrose gradient fractionation. Human tissue was homogenized in binding/lysis buffer $(50 \mathrm{mM}$ Tris (pH 7.4), $150 \mathrm{mM} \mathrm{NaCl}, 10 \%$ glycerol, and $1.0 \%$ Triton X-100) with protease and phosphatase inhibitors, followed by a brief sonication for $6 \mathrm{~s}$ at $20 \%$ amplitude. Total proteins were precipitated from monosome/polysome sucrose fractions using methanol/chloroform. Protein pellets were resuspended in a buffer containing $10 \mathrm{mM}$ Tris- $\mathrm{HCl} \mathrm{pH} 8$ and $0.1 \%$ SDS and used to run western blotting assays. The lysates or fractions were subjected to western blotting, as described previously ${ }^{103,155}$.

Ribosome profiling. Global RNase foot-printings were performed during three independent rounds of cell cultures $(n=3)$. For each round of global footprinting, mouse immortalized striatal cells (i.e., control, HD-het, and HD-homo cells) were plated in $15-\mathrm{cm}$ dishes at a confluency of $70 \%$. The following day, the medium was changed, and after $2 \mathrm{~h}$, the cells were incubated with CHX $(100 \mu \mathrm{g} / \mathrm{ml})$ for $10 \mathrm{~min}$ as in previous studies ${ }^{95,96}$. Cells were then scraped and washed with cold PBS (containing $100 \mu \mathrm{g} / \mathrm{ml} \mathrm{CHX)} \mathrm{twice.} \mathrm{During} \mathrm{the} \mathrm{second} \mathrm{wash,} \mathrm{5 \%} \mathrm{of} \mathrm{cells} \mathrm{were}$ transferred to different tubes and were lyzed by adding $700 \mu$ of QIAzol lysis reagent. Total RNAs of these samples were isolated using miRNeasy Mini Kit (Qiagen) for mRNA sequencing. After the second wash, the rest of the cells were lysed in a lysis buffer containing $20 \mathrm{mM}$ HEPES pH 7.3, $150 \mathrm{mM} \mathrm{KCl,} 10 \mathrm{mM}$ $\mathrm{MgCl}_{2}, 2 \mathrm{mM}$ DTT, $100 \mu \mathrm{g} / \mathrm{ml} \mathrm{CHX}, 0.5 \% \mathrm{v} / \mathrm{v}$ Triton X-100, $20 \mathrm{U} / \mathrm{ml}$ RNasin, and EDTA-free protease inhibitor cocktail (Roche). The cell lysates were passed 20 times through a $26-\mathrm{G}$ needle and incubated on ice for $15 \mathrm{~min}$, then centrifuged at $21,000 \times g$ for $15 \mathrm{~min}$. Supernatants were transferred to different tubes. Equal total RNA amount of each sample was used for global RNase footprinting as follows; for each A260 absorbance unit of the lysates 60 units of RNaseT1 (Thermo Fisher Scientific) and $0.6 \mu$ of RNaseA (Ambion) were added and the samples were incubated at $25^{\circ} \mathrm{C}$ for $30 \mathrm{~min}$. RNase-treated samples were immediately loaded on $10-50 \%$ sucrose gradients and centrifuged at $280,000 \times g$ (SW41Ti rotor) at $4{ }^{\circ} \mathrm{C}$ for $2 \mathrm{~h}$. Gradients were fractionated using a gradient fractionator and UA-6 detector, 254-nm filter (ISCO/BRANDEL). Fractions containing 80S peaks of each sample were collected, and their RNAs were isolated using a miRNeasy Mini Kit (Qiagen). The area under the curve for PS and 80S (MS) peaks in control and HD cells, using PeakChart (v. 2.08, BRANDEL), and expressed as a ratio of PS:MS.
Generation of cDNA libraries from ribosome-protected mRNAs. The following procedure was performed for all the RNA samples simultaneously. In total, $20 \mu \mathrm{g}$ of each sample was run on a 15\% TBE-Urea gel (Novex) along with 26 and 32 nt RNA markers. The gel containing each sample was excised between two markers. RNAs were extracted from gel pieces by incubating gel slurries with nuclease-free water overnight at $4{ }^{\circ} \mathrm{C}$ and precipitated using RNase-free isopropanol and then eluted in nuclease-free water. T4 polynucleotide kinase (NEB) was used to catalyze the addition of $5^{\prime}$ monophosphate and removal of the $3^{\prime}$ phosphate in the RNA fragments to leave a $3^{\prime}$ hydroxyl terminal needed for adapter ligation. RNA was purified using the Zymo clean and conc-5 kit (Zymo Research, Cat. no. R1013). Ribosomal RNA was depleted from the samples using TruSeq total RNA rRNAdepletion protocol (Illumina, Cat. no. RS-122-2201) and then RNA samples were purified using Agencourt RNAClean XP beads (Beckman Coulter).

Generation of cDNA libraries and sequencing. NEXTflex small RNA-Seq Kit v3 (Perkin Elmer) was used to ligate $5^{\prime}$ and $3^{\prime}$ adapters to purified RPF fragments, which then were reverse-transcribed and amplified (14 cycles) to generate cDNA libraries. Libraries were cleaned up using NEXTflex Cleanup beads, pooled and sequenced in the NextSeq 500 (V2) using single-end 50 bp chemistry at the Scripps Genomic Core, at FL, USA.

Generation of mRNA-Seq libraries. Total RNA extracted from the cultured striatal cells as noted under Ribosome profiling were used for mRNA-seq library preparation. NEBNext Ultra II Directional kit (NEB, Cat. no. E776) with the NEBNext poly(A) mRNA magnetic isolation module (NEB, Cat. no. E7490) was used to generate mRNA-Seq libraries. Briefly, $400 \mathrm{ng}$ of high-quality total RNA was used to purify poly(A) mRNA, fragmented, reverse-transcribed with random primers, adapter-ligated, and amplified according to the manufacturer's recommendations. The final libraries were validated on the bioanalyzer, pooled, and sequenced on the NextSeq 500 using paired-end 40 bp chemistry.

Ribo-Seq, RNA-Seq quality control, and mapping the reads to UCSC browser RNAseq reads were trimmed using Cutadapt v1.18 ${ }^{156}$ with the following parameters: -a AGATCGGAAGAGCACACGTCTGAACTCCAGTCA -A AGATC GGAAGAGCGTCGTGTAGGGAAAGAGTGT-minimum-length=15 -pair-filter=any. For Ribo-Seq reads, $3^{\prime}$ adapters were trimmed using Cutadapt with the following parameters: -a TGGAATTCTCGGGTGCCAAGG-minimum-length 23. The reads were further trimmed using Cutadapt to remove four bases from either side of each read accordingly to the NEXTflex ${ }^{\text {min }}$ Small RNA Trimming Instructions (cutadapt -u $4-\mathrm{u}-4$ ). Fastq files were checked for quality control with FastQC v0.11.8. Both RNA-Seq and Ribo-Seq reads were next mapped to a library of mouse rRNA and tRNA sequences using Bowtie v1.1.2. Any reads mapping to these abundant contaminants were filtered out. The remaining reads were then aligned to the mouse transcriptome with RSEM v1.3.0157 using the GRCm38.p5 genome annotation and the comprehensive gene annotation from Gencode (M16 release) as transcriptome reference. Reads with a mapping quality $<5$ were discarded. Cleaned bam files were converted to bigWig files with Bedtools v2.27.0158 for visualization using the UCSC Genome Browser. For the Euclidian distance analyses, gene expression was quantified with RSEM v1.3.0, and comparison plots were generated in R using DESeq2 v1.22.2 $2^{159}$ and ggplot2 v3.3.0 packages. Statistical testing was done using DESeq2 with a two-tailed Wald test and adjusted for multiple comparisons using the procedure of Benjamini-Hochberg ${ }^{160}$.

Ribosome occupancy (Anato2Seq) analysis. The raw Ribo-Seq reads were clipped of adapter sequence (TGGAATTCTCGGGTGCCAAGG) using Cutadapt (version 1.18) ${ }^{156}$ with the following command: cutadapt -f fastq -a

CTGTAGGCACCATCAAT-minimum-length $=23<$ input $>$.fastq $-0<$ output $>$. fastq. A 4 bp secondary trim from either end of the reads was performed also using Cutadapt. Mouse rRNA sequences were retrieved from NCBI ${ }^{161}$ with the following accessions: NR_003279, NR_003278, NR_003280, NR_030686. Ribo-Seq and RNA-Seq reads aligning to these sequences were removed using bowtie (version 1.0.1) $)^{162}$ with the following command: bowtie -v 3-norc <path_to_rRNA_indices $>-\mathrm{q}<$ input $>$.fastq-un $<$ output $>$. fastq. The remaining reads were then mapped using bowtie to the RefSeq ${ }^{163}$ mouse transcriptome downloaded from ftp://ftp.ncbi. nlm.nih.gov/refseq/M_musculus/mRNA_Prot/ on October 9, 2018. The following command was used: bowtie -a -m $100-125-\mathrm{n} 2$-S-norc <path_to_transcriptome_indices $>-\mathrm{q}<$ input $>$.fastq $<$ output $>$.sam

The sam alignment files were parsed with an in-house python script to count the number of reads aligned to each gene using an exon union approach ${ }^{164}$. The Ribo-Seq reads were assigned to mRNA coordinates using an offset of 14 nucleotides downstream of the $5^{\prime}$ end of the reads. The counts included uniquely mapped reads i.e., reads that mapped to one location only in the mouse transcriptome plus reads that mapped up to 3 locations in the transcriptome which were weighted by the number of their mapped locations (up to 3 ).

For differential expression analysis using Anota2seq ${ }^{97}$, the number of reads aligning to annotated CDS regions was used for Ribo-Seq while for RNA-Seq the number of reads aligning to the entire transcript was used. These counts were input to anota2seq (version 1.5.2) with the parameters dataType = "RNAseq", filterZeroGenes = FALSE, normalize = TRUE, transformation = "TMM-log2". All 
statistical tests within the anota2seq package are two-tailed. Violin plots were generated using $\mathrm{R}$ version 4.0.2 (2020-06-22) to show the distribution of ribosome occupancy changes ${ }^{165}$

Ribosome pause (PausePred) analysis. The command-line version of the PausePred software ${ }^{100,164}$ was run with the following parameters for each replicate (control, HD-het and HD-homo): fold change: 5; window size: 1000 nucleotides; read lengths: 26-32 nucleotides; window coverage: 5 . Individual offset values were assigned according to metagene analysis for each read length (26-32 nucleotides) accounting for mismatches at the $5^{\prime}$ ends of the reads. For genes with detected pauses, the center of ribosome density ${ }^{166}$ was determined using an in-house python script.

CDNA preparation and real-time PCR. A sucrose density gradient centrifugation was carried out using control and HD-homo cells, and ribosome fractions were collected. RNA was extracted from the fractionated samples following lysis in Trizol reagent. In total, $250 \mathrm{ng}$ of RNA was used to prepare cDNA using Takara primescript $^{\text {tm }}$ kit (Cat no. 6110A) using random hexamers. The qRT-PCR of genes was performed with SYBR green (Takara RR420A) reagents. Primers for all the genes were designed based on sequences available from the Harvard qPCR primer bank.

The total mRNA-Seq data of control and HD-homo cells was used to estimate the Fmrl and actin mRNA reads. The mRNA was isolated from the striatal tissue of unaffected and HD patient striatum (grade 1 and grade 2) and qPCR for FMR1 or GAPDH were done as described ${ }^{103}$. Relative mRNA expression of Fmr1 was determined after normalization with Actin or Gapdh transcripts. The list of PCR primers used in this study is listed in Supplementary Table 3.

Statistical analysis. Data are presented as mean \pm SEM as indicated. Except where stated all experiments were performed at least in three biological replicates and repeated at least twice. Statistical comparison was performed between groups using two-tailed Student's $t$ test, one-way analysis of variance (ANOVA) followed by Tukey's multiple comparison test or Bonferroni's multiple comparisons test and two-way ANOVA or two-way repeated measures ANOVA followed by Tukey's multiple comparison test or Bonferroni post-hoc test as indicated in the figure legends. Significance was set at $P<0.05$. All statistical tests were performed using Prism 7.0 (GraphPad software).

Reporting summary. Further information on research design is available in the Nature Research Reporting Summary linked to this article.

\section{Data availability}

The complete dataset from the analysis of the HTT interactors from healthy and HD fibroblasts (raw files, identification data, and data analysis files) can be obtained via ProteomeXchange with identifier PXD017115. The data for the Ribo-Seq and RNA-Seq reported in this study are openly available in Gene Expression Omnibus at accession number GSE146675. UCSC browser information to view genome browser hub with the RNA-Seq and Ribo-Seq data: To find genes of your interests, go to the Genome browser website (http://genome.ucsc.edu) and then click on "My Data > Track Hubs". Then paste the link https://data.cyverse.org/dav-anon/iplant/home/rmi2lab/Hub_Collaborations/ Srini/hub.txt in the "url" field and click on "Add hub." After the hub is loaded, go to "Genomes > Mouse GRCm38/mm10". Once you reach the actual browser window, you will have to scroll down to the bottom menu. Find a section (the one at the top of the menu) named "Srini" to activate the different tracks. The data supporting the findings of this study are available from the corresponding authors upon reasonable request. Source data are provided with this paper.

Received: 25 February 2020; Accepted: 29 January 2021; Published online: 05 March 2021

\section{References}

1. Buskirk, A. R. \& Green, R. Ribosome pausing, arrest and rescue in bacteria and eukaryotes. Philos. Trans. R Soc. Lond. B Biol. Sci. 372, 20160183 (2017).

2. Joazeiro, C. A. P. Mechanisms and functions of ribosome-associated protein quality control. Nat. Rev. Mol. Cell Biol. 20, 368-383 (2019).

3. Schuller, A. P. \& Green, R. Roadblocks and resolutions in eukaryotic translation. Nat. Rev. Mol. Cell Biol. 19, 526-541 (2018).

4. Brandman, O. \& Hegde, R. S. Ribosome-associated protein quality control. Nat. Struct. Mol. Biol. 23, 7-15 (2016).

5. Neubauer, C., Gillet, R., Kelley, A. C. \& Ramakrishnan, V. Decoding in the absence of a codon by tmRNA and SmpB in the ribosome. Science 335, 1366-1369 (2012).

6. Brown, A., Fernandez, I. S., Gordiyenko, Y. \& Ramakrishnan, V. Ribosomedependent activation of stringent control. Nature 534, 277-280 (2016).
7. James, N. R., Brown, A., Gordiyenko, Y. \& Ramakrishnan, V. Translational termination without a stop codon. Science 354, 1437-1440 (2016).

8. Joazeiro, C. A. P. Ribosomal stalling during translation: providing substrates for ribosome-associated protein quality control. Annu. Rev. Cell Dev. Biol. 33 343-368 (2017).

9. Ishimura, R. et al. RNA function. Ribosome stalling induced by mutation of a CNS-specific tRNA causes neurodegeneration. Science 345, 455-459 (2014).

10. Russo, A. et al. Increased cytoplasmic TDP-43 reduces global protein synthesis by interacting with RACK1 on polyribosomes. Hum. Mol. Genet. 26, 1407-1418 (2017)

11. Higashi, S. et al. TDP-43 associates with stalled ribosomes and contributes to cell survival during cellular stress. J. Neurochem. 126, 288-300 (2013).

12. Gabanella, F. et al. SMN affects membrane remodelling and anchoring of the protein synthesis machinery. J. Cell Sci. 129, 804-816 (2016).

13. Bernabo, $P$. et al. In vivo translatome profiling in spinal muscular atrophy reveals a role for SMN protein in ribosome biology. Cell Rep. 21, 953-965 (2017).

14. Lopez-Erauskin, J. et al. ALS/FTD-linked mutation in FUS suppresses intraaxonal protein synthesis and drives disease without nuclear loss-of-function of FUS. Neuron 100, 816-830 e817 (2018).

15. Fittschen, M. et al. Genetic ablation of ataxin-2 increases several global translation factors in their transcript abundance but decreases translation rate. Neurogenetics 16, 181-192 (2015).

16. Darnell, J. C. et al. FMRP stalls ribosomal translocation on mRNAs linked to synaptic function and autism. Cell 146, 247-261 (2011).

17. Shah, S. et al. FMRP control of ribosome translocation promotes chromatin modifications and alternative splicing of neuronal genes linked to autism. Cell Rep. 30, 4459-4472 e4456 (2020).

18. Darnell, J. C. \& Klann, E. The translation of translational control by FMRP: therapeutic targets for FXS. Nat. Neurosci. 16, 1530-1536 (2013).

19. Willemsen, R., Levenga, J. \& Oostra, B. A. CGG repeat in the FMR1 gene: size matters. Clin. Genet. 80, 214-225 (2011).

20. Cabal-Herrera, A. M., Tassanakijpanich, N., Salcedo-Arellano, M. J. \& Hagerman, R. J. Fragile X-associated tremor/ataxia syndrome (FXTAS): pathophysiology and clinical implications. Int. J. Mol. Sci. 21, 4391 (2020).

21. Choe, Y. J. et al. Failure of RQC machinery causes protein aggregation and proteotoxic stress. Nature 531, 191-195 (2016).

22. Duyao, M. P. et al. Inactivation of the mouse Huntington's disease gene homolog Hdh. Science 269, 407-410 (1995).

23. Nasir, J. et al. Targeted disruption of the Huntington's disease gene results in embryonic lethality and behavioral and morphological changes in heterozygotes. Cell 81, 811-823 (1995).

24. Zeitlin, S., Liu, J. P., Chapman, D. L., Papaioannou, V. E. \& Efstratiadis, A. Increased apoptosis and early embryonic lethality in mice nullizygous for the Huntington's disease gene homologue. Nat. Genet. 11, 155-163 (1995).

25. White, J. K. et al. Huntingtin is required for neurogenesis and is not impaired by the Huntington's disease CAG expansion. Nat. Genet. 17, 404-410 (1997).

26. Wang, G., Liu, X., Gaertig, M. A., Li, S. \& Li, X. J. Ablation of huntingtin in adult neurons is nondeleterious but its depletion in young mice causes acute pancreatitis. Proc. Natl Acad. Sci. USA 113, 3359-3364 (2016).

27. Dragatsis, I. et al. Effect of early embryonic deletion of huntingtin from pyramidal neurons on the development and long-term survival of neurons in cerebral cortex and striatum. Neurobiol. Dis. 111, 102-117 (2018).

28. Burrus, C. J. et al. Striatal projection neurons require huntingtin for synaptic connectivity and survival. Cell Rep. 30, 642-657 e646 (2020).

29. Baig, S. S., Strong, M. \& Quarrell, O. W. The global prevalence of Huntington's disease: a systematic review and discussion. Neurodegener. Dis. Manag. 6, 331-343 (2016).

30. Finkbeiner, S. Huntington's disease. Cold Spring Harb Perspect. Biol. 3, a007476 (2011).

31. Ricco, M., Vezzosi, L., Balzarini, F., Gualerzi, G. \& Ranzieri, S. Prevalence of Huntington Disease in Italy: a systematic review and meta-analysis. Acta Biomed. 91, 119-127 (2020).

32. Barnat, M. et al. Huntington's disease alters human neurodevelopment. Science 369, 787-793 (2020).

33. DiFiglia, M. An early start to Huntington's disease. Science 369, 771-772 (2020).

34. Lewandowski, N. M. et al. Regional vulnerability in Huntington's disease: fMRI-guided molecular analysis in patients and a mouse model of disease. Neurobiol. Dis. 52, 84-93 (2013).

35. McColgan, P. et al. Brain regions showing white matter loss in Huntington's disease are enriched for synaptic and metabolic genes. Biol. Psychiatry 83, 456-465 (2018)

36. Halliday, G. M. et al. Regional specificity of brain atrophy in Huntington's disease. Exp. Neurol. 154, 663-672 (1998).

37. Kassubek, J. et al. Topography of cerebral atrophy in early Huntington's disease: a voxel based morphometric MRI study. J. Neurol. Neurosurg. Psychiatry 75, 213-220 (2004). 
38. Waldvogel, H. J., Kim, E. H., Tippett, L. J., Vonsattel, J. P. \& Faull, R. L. The neuropathology of Huntington's disease. Curr. Top. Behav. Neurosci. 22, 33-80 (2015).

39. Mochel, F. et al. Early alterations of brain cellular energy homeostasis in Huntington disease models. J. Biol. Chem. 287, 1361-1370 (2012).

40. Subramaniam, S. \& Snyder, S. H. Huntington's disease is a disorder of the corpus striatum: focus on Rhes (Ras homologue enriched in the striatum). Neuropharmacology 60, 1187-1192 (2011).

41. Wexler, N. S. et al. Homozygotes for Huntington's disease. Nature 326 194-197 (1987).

42. Squitieri, F. et al. Homozygosity for CAG mutation in Huntington disease is associated with a more severe clinical course. Brain 126, 946-955 (2003).

43. DiFiglia, M. et al. Huntingtin is a cytoplasmic protein associated with vesicles in human and rat brain neurons. Neuron 14, 1075-1081 (1995).

44. Velier, J. et al. Wild-type and mutant huntingtins function in vesicle trafficking in the secretory and endocytic pathways. Exp. Neurol. 152, 34-40 (1998).

45. Steffan, J. S. et al. The Huntington's disease protein interacts with p53 and CREB-binding protein and represses transcription. Proc. Natl Acad. Sci. USA 97, 6763-6768 (2000).

46. Zuccato, C. et al. Loss of huntingtin-mediated BDNF gene transcription in Huntington's disease. Science 293, 493-498 (2001).

47. Nucifora, F. C. Jr. et al. Interference by huntingtin and atrophin-1 with cbpmediated transcription leading to cellular toxicity. Science 291, 2423-2428 (2001).

48. Hoffner, G., Kahlem, P. \& Djian, P. Perinuclear localization of huntingtin as a consequence of its binding to microtubules through an interaction with beta-tubulin: relevance to Huntington's disease. J. Cell Sci. 115, 941-948 (2002).

49. Takano, H. \& Gusella, J. F. The predominantly HEAT-like motif structure of huntingtin and its association and coincident nuclear entry with dorsal, an NF-kB/Rel/dorsal family transcription factor. BMC Neurosci. 3, 15 (2002).

50. Kegel, K. B. et al. Huntingtin is present in the nucleus, interacts with the transcriptional corepressor C-terminal binding protein, and represses transcription. J. Biol. Chem. 277, 7466-7476 (2002).

51. Sipione, S. et al. Early transcriptional profiles in huntingtin-inducible striatal cells by microarray analyses. Hum. Mol. Genet. 11, 1953-1965 (2002).

52. Xia, J., Lee, D. H., Taylor, J., Vandelft, M. \& Truant, R. Huntingtin contains a highly conserved nuclear export signal. Hum. Mol. Genet. 12, 1393-1403 (2003).

53. Tang, T. S. et al. Huntingtin and huntingtin-associated protein 1 influence neuronal calcium signaling mediated by inositol- $(1,4,5)$ triphosphate receptor type 1. Neuron 39, 227-239 (2003).

54. Gafni, J. et al. Inhibition of calpain cleavage of huntingtin reduces toxicity: accumulation of calpain/caspase fragments in the nucleus. J. Biol. Chem. 279, 20211-20220 (2004).

55. Maglione, V., Cannella, M., Gradini, R., Cislaghi, G. \& Squitieri, F. Huntingtin fragmentation and increased caspase 3, 8 and 9 activities in lymphoblasts with heterozygous and homozygous Huntington's disease mutation. Mech. Ageing Dev. 127, 213-216 (2006).

56. Graham, R. K. et al. Cleavage at the caspase- 6 site is required for neuronal dysfunction and degeneration due to mutant huntingtin. Cell 125, 1179-1191 (2006).

57. Yamamoto, A., Cremona, M. L. \& Rothman, J. E. Autophagy-mediated clearance of huntingtin aggregates triggered by the insulin-signaling pathway. J. Cell Biol. 172, 719-731 (2006).

58. Zhang, H. et al. Elucidating a normal function of huntingtin by functional and microarray analysis of huntingtin-null mouse embryonic fibroblasts. BMC Neurosci. 9, 38 (2008).

59. Landles, C. et al. Proteolysis of mutant huntingtin produces an exon 1 fragment that accumulates as an aggregated protein in neuronal nuclei in Huntington disease. J. Biol. Chem. 285, 8808-8823 (2010).

60. Brandstaetter, H., Kruppa, A. J. \& Buss, F. Huntingtin is required for ER-toGolgi transport and for secretory vesicle fusion at the plasma membrane. Dis. Model Mech. 7, 1335-1340 (2014).

61. Paul, B. D. et al. Cystathionine gamma-lyase deficiency mediates neurodegeneration in Huntington's disease. Nature 509, 96-100 (2014).

62. Moruno Manchon, J. F. et al. Cytoplasmic sphingosine-1-phosphate pathway modulates neuronal autophagy. Sci. Rep. 5, 15213 (2015).

63. $\mathrm{O}^{\prime}$ Brien, R. et al. Integration-independent transgenic Huntington disease fragment mouse models reveal distinct phenotypes and life span in vivo. $J$. Biol. Chem. 290, 19287-19306 (2015).

64. Shema, R. et al. Synthetic lethal screening in the mammalian central nervous system identifies Gpx6 as a modulator of Huntington's disease. Proc. Natl Acad. Sci. USA 112, 268-272 (2015).

65. Sbodio, J. I., Snyder, S. H. \& Paul, B. D. Transcriptional control of amino acid homeostasis is disrupted in Huntington's disease. Proc. Natl Acad. Sci. USA 113, 8843-8848 (2016).
66. Aron, R. et al. Deubiquitinase Usp12 functions noncatalytically to induce autophagy and confer neuroprotection in models of Huntington's disease. Nat. Commun. 9, 3191 (2018)

67. Di Pardo, A. et al. Treatment with K6PC-5, a selective stimulator of SPHK1, ameliorates intestinal homeostasis in an animal model of Huntington's disease. Neurobiol. Dis. 143, 105009 (2020).

68. Lee, H. et al. Cell type-specific transcriptomics reveals that mutant Huntingtin leads to mitochondrial RNA release and neuronal innate immune activation. Neuron 107, 891-908 e898 (2020).

69. Jauhari, A. et al. Melatonin inhibits cytosolic mitochondrial DNA-induced neuroinflammatory signaling in accelerated aging and neurodegeneration. $J$. Clin. Investig. 130, 3124-3136 (2020)

70. Fossale, E. et al. Identification of a presymptomatic molecular phenotype in Hdh CAG knock-in mice. Hum. Mol. Genet. 11, 2233-2241 (2002).

71. Wyttenbach, A. et al. Polyglutamine expansions cause decreased CREmediated transcription and early gene expression changes prior to cell death in an inducible cell model of Huntington's disease. Hum. Mol. Genet. 10, 1829-1845 (2001).

72. Iqbal, K., Tellez-Nagel, I. \& Grundke-Iqbal, I. Protein abnormalities in Huntington's chorea. Brain Res. 76, 178-184 (1974)

73. Tauber, E. et al. Functional gene expression profiling in yeast implicates translational dysfunction in mutant huntingtin toxicity. J. Biol. Chem. 286 410-419 (2011).

74. Runne, H. et al. Dysregulation of gene expression in primary neuron models of Huntington's disease shows that polyglutamine-related effects on the striatal transcriptome may not be dependent on brain circuitry. J. Neurosci. 28, 9723-9731 (2008)

75. Culver, B. P. et al. Proteomic analysis of wild-type and mutant huntingtinassociated proteins in mouse brains identifies unique interactions and involvement in protein synthesis. J. Biol. Chem. 287, 21599-21614 (2012).

76. Joag, $\mathrm{H}$. et al. A role of cellular translation regulation associated with toxic Huntingtin protein. Cell Mol. Life Sci. 77, 3657-3670 (2020).

77. Sap, K. A. et al. Global proteome and ubiquitinome changes in the soluble and insoluble fractions of Q175 Huntington mice brains. Mol. Cell Proteom. 18, 1705-1720 (2019)

78. Kim, Y. E. et al. Soluble oligomers of PolyQ-expanded Huntingtin target a multiplicity of key cellular factors. Mol. Cell 63, 951-964 (2016).

79. Hidalgo San Jose, L. \& Signer, R. A. J. Cell-type-specific quantification of protein synthesis in vivo. Nat. Protoc. 14, 441-460 (2019).

80. Trettel, F. et al. Dominant phenotypes produced by the HD mutation in STHdh(Q111) striatal cells. Hum. Mol. Genet. 9, 2799-2809 (2000).

81. Schmidt, E. K., Clavarino, G., Ceppi, M. \& Pierre, P. SUnSET, a nonradioactive method to monitor protein synthesis. Nat. Methods 6, 275-277 (2009).

82. Ingolia, N. T., Lareau, L. F. \& Weissman, J. S. Ribosome profiling of mouse embryonic stem cells reveals the complexity and dynamics of mammalian proteomes. Cell 147, 789-802 (2011).

83. Yan, X., Hoek, T. A., Vale, R. D. \& Tanenbaum, M. E. Dynamics of translation of single mRNA molecules in vivo. Cell 165, 976-989 (2016).

84. Huang, M. T. Harringtonine, an inhibitor of initiation of protein biosynthesis Mol. Pharm. 11, 511-519 (1975).

85. Fresno, M., Jimenez, A. \& Vazquez, D. Inhibition of translation in eukaryotic systems by harringtonine. Eur. J. Biochem. 72, 323-330 (1977).

86. Barry, K. C., Ingolia, N. T. \& Vance, R. E. Global analysis of gene expression reveals mRNA superinduction is required for the inducible immune response to a bacterial pathogen. eLife 6, e22707 (2017)

87. Sivan, G., Kedersha, N. \& Elroy-Stein, O. Ribosomal slowdown mediates translational arrest during cellular division. Mol. Cell Biol. 27, 6639-6646 (2007).

88. Azzam, M. E. \& Algranati, I. D. Mechanism of puromycin action: fate of ribosomes after release of nascent protein chains from polysomes. Proc. Natl Acad. Sci. USA 70, 3866-3869 (1973).

89. Ratovitski, T. et al. Huntingtin protein interactions altered by polyglutamine expansion as determined by quantitative proteomic analysis. Cell Cycle 11, 2006-2021 (2012)

90. Scherzinger, E. et al. Self-assembly of polyglutamine-containing huntingtin fragments into amyloid-like fibrils: implications for Huntington's disease pathology. Proc. Natl Acad. Sci. USA 96, 4604-4609 (1999).

91. Ingolia, N. T., Ghaemmaghami, S., Newman, J. R. \& Weissman, J. S. Genomewide analysis in vivo of translation with nucleotide resolution using ribosome profiling. Science 324, 218-223 (2009).

92. Brar, G. A. et al. High-resolution view of the yeast meiotic program revealed by ribosome profiling. Science 335, 552-557 (2012).

93. Zhang, S. et al. Analysis of ribosome stalling and translation elongation dynamics by deep learning. Cell Syst. 5, 212-220 e216 (2017).

94. Kim, J. K. \& Hollingsworth, M. J. Localization of in vivo ribosome pause sites Anal. Biochem 206, 183-188 (1992).

95. Guo, H., Ingolia, N. T., Weissman, J. S. \& Bartel, D. P. Mammalian microRNAs predominantly act to decrease target mRNA levels. Nature 466, 835-840 (2010). 
96. Miettinen, T. P. \& Bjorklund, M. Modified ribosome profiling reveals high abundance of ribosome protected mRNA fragments derived from $3^{\prime}$ untranslated regions. Nucleic Acids Res. 43, 1019-1034 (2015).

97. Oertlin, C. et al. Generally applicable transcriptome-wide analysis of translation using anota2seq. Nucleic Acids Res. 47, e70 (2019).

98. Liu, B. et al. Regulatory discrimination of mRNAs by FMRP controls mouse adult neural stem cell differentiation. Proc. Natl Acad. Sci. USA 115, E11397-E11405 (2018).

99. Cha, J. H. Transcriptional signatures in Huntington's disease. Prog. Neurobiol. 83, 228-248 (2007).

100. Kumari, R., Michel, A. M. \& Baranov, P. V. PausePred and Rfeet: webtools for inferring ribosome pauses and visualizing footprint density from ribosome profiling data. RNA 24, 1297-1304 (2018).

101. Ingvarsson, S., Asker, C., Axelson, H., Klein, G. \& Sumegi, J. Structure and expression of B-myc, a new member of the myc gene family. Mol. Cell Biol. 8, 3168-3174 (1988).

102. Sun, L., Wu, J., Du, F., Chen, X. \& Chen, Z. J. Cyclic GMP-AMP synthase is a cytosolic DNA sensor that activates the type I interferon pathway. Science 339, 786-791 (2013).

103. Sharma, M., Rajendrarao, S., Shahani, N., Ramirez-Jarquin, U. N. \& Subramaniam, S. Cyclic GMP-AMP synthase promotes the inflammatory and autophagy responses in Huntington disease. Proc. Natl Acad. Sci. USA 117, 15989-15999 (2020).

104. Banerjee, A., Ifrim, M. F., Valdez, A. N., Raj, N. \& Bassell, G. J. Aberrant RNA translation in fragile $\mathrm{X}$ syndrome: from FMRP mechanisms to emerging therapeutic strategies. Brain Res. 1693, 24-36 (2018).

105. Nalavadi, V. C., Muddashetty, R. S., Gross, C. \& Bassell, G. J. Dephosphorylation-induced ubiquitination and degradation of FMRP in dendrites: a role in immediate early mGluR-stimulated translation. J. Neurosci. 32, 2582-2587 (2012).

106. Muddashetty, R. S. et al. Reversible inhibition of PSD-95 mRNA translation by miR-125a, FMRP phosphorylation, and mGluR signaling. Mol. Cell 42, 673-688 (2011).

107. Valdez-Sinon, A. N. et al. Cdh1-APC regulates protein synthesis and stress granules in neurons through an FMRP-dependent mechanism. iScience 23, 101132 (2020).

108. Culver, B. P. et al. Huntington's disease protein Huntingtin associates with its own mRNA. J. Huntingt. Dis. 5, 39-51 (2016).

109. Shen, M. et al. Reduced mitochondrial fusion and Huntingtin levels contribute to impaired dendritic maturation and behavioral deficits in Fmr1-mutant mice. Nat. Neurosci. 22, 386-400 (2019).

110. Xu, F., Kula-Eversole, E., Iwanaszko, M., Lim, C. \& Allada, R. Ataxin2 functions via CrebA to mediate Huntingtin toxicity in circadian clock neurons. PLoS Genet. 15, e1008356 (2019).

111. Shu, H. et al. FMRP links optimal codons to mRNA stability in neurons. Proc. Natl Acad. Sci. USA 117, 30400-30411 (2020).

112. Greenough, W. T. et al. Synaptic regulation of protein synthesis and the fragile X protein. Proc. Natl Acad. Sci. USA 98, 7101-7106 (2001).

113. Yan, J., Porch, M. W., Court-Vazquez, B., Bennett, M. V. L. \& Zukin, R. S. Activation of autophagy rescues synaptic and cognitive deficits in fragile $\mathrm{X}$ mice. Proc. Natl Acad. Sci. USA 115, E9707-E9716 (2018).

114. Davis, J. K. \& Broadie, K. Multifarious functions of the fragile X mental retardation protein. Trends Genet 33, 703-714 (2017).

115. Moily, N. S. et al. Transcriptional profiles for distinct aggregation states of mutant Huntingtin exon 1 protein unmask new Huntington's disease pathways. Mol. Cell Neurosci. 83, 103-112 (2017).

116. Yablonska, S. et al. Mutant huntingtin disrupts mitochondrial proteostasis by interacting with TIM23. Proc. Natl Acad. Sci. USA 116, 16593-16602 (2019).

117. Hsieh, A. C. et al. The translational landscape of mTOR signalling steers cancer initiation and metastasis. Nature 485, 55-61 (2012).

118. Pryor, W. M. et al. Huntingtin promotes mTORC1 signaling in the pathogenesis of Huntington's disease. Sci. Signal 7, ra103 (2014).

119. Tyagi, R. et al. Rheb inhibits protein synthesis by activating the PERKeIF2alpha signaling cascade. Cell Rep. 10, 684-693 (2015).

120. Creus-Muncunill, J. et al. Increased translation as a novel pathogenic mechanism in Huntington's disease. Brain 142, 3158-3175 (2019).

121. Kobe, B. et al. Turn up the HEAT. Structure 7, R91-R97 (1999).

122. Andrade, M. A., Petosa, C., O'Donoghue, S. I., Muller, C. W. \& Bork, P. Comparison of ARM and HEAT protein repeats. J. Mol. Biol. 309, 1-18 (2001).

123. Andersen, C. B. et al. Structure of eEF3 and the mechanism of transfer RNA release from the E-site. Nature 443, 663-668 (2006).

124. Anand, M., Chakraburtty, K., Marton, M. J., Hinnebusch, A. G. \& Kinzy, T. G. Functional interactions between yeast translation eukaryotic elongation factor (eEF) 1A and eEF3. J. Biol. Chem. 278, 6985-6991 (2003).

125. Gontarek, R. R., Li, H., Nurse, K. \& Prescott, C. D. The N terminus of eukaryotic translation elongation factor 3 interacts with $18 \mathrm{~S}$ rRNA and $80 \mathrm{~S}$ ribosomes. J. Biol. Chem. 273, 10249-10252 (1998).
126. Dever, T. E., Kinzy, T. G. \& Pavitt, G. D. Mechanism and regulation of protein synthesis in Saccharomyces cerevisiae. Genetics 203, 65-107 (2016).

127. El-Daher, M. T. et al. Huntingtin proteolysis releases non-polyQ fragments that cause toxicity through dynamin 1 dysregulation. EMBO J. 34, 2255-2271 (2015).

128. Ehrnhoefer, D. E. et al. Preventing mutant huntingtin proteolysis and intermittent fasting promote autophagy in models of Huntington disease. Acta Neuropathol. Commun. 6, 16 (2018).

129. Ramdzan, Y. M. et al. Huntingtin inclusions trigger cellular quiescence, deactivate apoptosis, and lead to delayed necrosis. Cell Rep. 19, 919-927 (2017).

130. Ormsby, A. R. et al. Nascent mutant Huntingtin exon 1 chains do not stall on ribosomes during translation but aggregates do recruit machinery involved in ribosome quality control and RNA. PLoS ONE 15, e0233583 (2020).

131. Arrasate, M. \& Finkbeiner, S. Protein aggregates in Huntington's disease. Exp. Neurol. 238, 1-11 (2012).

132. Kruttner, S. et al. Synaptic Orb2A bridges memory acquisition and late memory consolidation in Drosophila. Cell Rep. 11, 1953-1965 (2015).

133. Xu, S., Tyagi, S. \& Schedl, P. Spermatid cyst polarization in Drosophila depends upon apkc and the CPEB family translational regulator orb2. PLoS Genet. 10, e1004380 (2014)

134. Banerjee, S., Ferdosh, S., Ghosh, A. N. \& Barat, C. Tau protein-induced sequestration of the eukaryotic ribosome: Implications in neurodegenerative disease. Sci. Rep. 10, 5225 (2020).

135. Maziuk, B., Ballance, H. I. \& Wolozin, B. Dysregulation of RNA binding protein aggregation in neurodegenerative disorders. Front. Mol. Neurosci. 10, 89 (2017).

136. Pechmann, S., Willmund, F. \& Frydman, J. The ribosome as a hub for protein quality control. Mol. Cell 49, 411-421 (2013).

137. Subramaniam, S. Selective neuronal death in neurodegenerative diseases: the ongoing mystery. Yale J. Biol. Med. 92, 695-705 (2019).

138. Creus-Muncunill, J. \& Ehrlich, M. E. Cell-autonomous and non-cellautonomous pathogenic mechanisms in Huntington's disease: insights from in vitro and in vivo models. Neurotherapeutics 16, 957-978 (2019).

139. Subramaniam, S., Sixt, K. M., Barrow, R. \& Snyder, S. H. Rhes, a striatal specific protein, mediates mutant-huntingtin cytotoxicity. Science 324, 1327-1330 (2009).

140. Swarnkar, S. et al. Ectopic expression of the striatal-enriched GTPase Rhes elicits cerebellar degeneration and an ataxia phenotype in Huntington's disease. Neurobiol. Dis. 82, 66-77 (2015).

141. Steffan, J. S. et al. SUMO modification of Huntingtin and Huntington's disease pathology. Science 304, 100-104 (2004).

142. Okamoto, S. et al. Balance between synaptic versus extrasynaptic NMDA receptor activity influences inclusions and neurotoxicity of mutant huntingtin. Nat. Med. 15, 1407-1413 (2009).

143. Seredenina, T., Gokce, O. \& Luthi-Carter, R. Decreased striatal RGS2 expression is neuroprotective in Huntington's disease (HD) and exemplifies a compensatory aspect of HD-induced gene regulation. PLOS ONE 6, e22231 (2011).

144. Baiamonte, B. A., Lee, F. A., Brewer, S. T., Spano, D. \& LaHoste, G. J. Attenuation of Rhes activity significantly delays the appearance of behavioral symptoms in a mouse model of Huntington's disease. PLoS ONE 8, e53606 (2013).

145. Sbodio, J. I., Paul, B. D., Machamer, C. E. \& Snyder, S. H. Golgi protein ACBD3 mediates neurotoxicity associated with Huntington's disease. Cell Rep. 4, 890-897 (2013)

146. Lu, B. \& Palacino, J. A novel human embryonic stem cell-derived Huntington's disease neuronal model exhibits mutant huntingtin (mHTT) aggregates and soluble mHTT-dependent neurodegeneration. FASEB J. 27, 1820-1829 (2013)

147. Argenti, M. The Role of Mitochondrial Dysfunction in Huntington's Disease Pathogenesis and its Relation with Striatal RHES Protein. Ph.D Thesis, Università degli Studi di Padova (2014)

148. Liu, Q. et al. Loss of Hap1 selectively promotes striatal degeneration in Huntington disease mice. Proc. Natl Acad. Sci. USA 117, 20265-20273 (2020).

149. Sharma, M. \& Subramaniam, S. Rhes travels from cell to cell and transports Huntington disease protein via TNT-like protrusion. J. Cell Biol. 218, 1972-1993 (2019).

150. Subramaniam, S. et al. Rhes, a striatal-enriched small G protein, mediates mTOR signaling and L-DOPA-induced dyskinesia. Nat. Neurosci. 15, 191-193 (2011).

151. Ma, X. M. \& Blenis, J. Molecular mechanisms of mTOR-mediated translational control. Nat. Rev. Mol. Cell Biol. 10, 307-318 (2009).

152. Thoreen, C. C. The molecular basis of mTORC1-regulated translation. Biochem Soc. Trans. 45, 213-221 (2017).

153. Margulis, J. \& Finkbeiner, S. Proteostasis in striatal cells and selective neurodegeneration in Huntington's disease. Front. Cell Neurosci. 8, 218 (2014). 
154. Shahani, N. et al. RasGRP1 promotes amphetamine-induced motor behavior through a Rhes interaction network ("Rhesactome") in the striatum. Sci. Signal 9, ra111 (2016)

155. Sharma, M. et al. Rhes, a striatal-enriched protein, promotes mitophagy via Nix. Proc. Natl Acad. Sci. USA 116, 23760-23771 (2019).

156. Martin, M. Cutadapt removes adapter sequences from high-throughput sequencing reads. EMBnet. J. 17, 10-12 (2011).

157. Li, B. \& Dewey, C. N. RSEM: accurate transcript quantification from RNA-Seq data with or without a reference genome. BMC Bioinforma. 12, 323 (2011).

158. Quinlan, A. R. \& Hall, I. M. BEDTools: a flexible suite of utilities for comparing genomic features. Bioinformatics 26, 841-842 (2010).

159. Love, M. I., Huber, W. \& Anders, S. Moderated estimation of fold change and dispersion for RNA-seq data with DESeq2. Genome Biol. 15, 550 (2014).

160. Anders, S. \& Huber, W. Differential expression analysis for sequence count data. Genome Biol. 11, R106 (2010).

161. Coordinators, N. R. Database resources of the national center for biotechnology information. Nucleic Acids Res. 46, D8-D13 (2018).

162. Langmead, B., Trapnell, C., Pop, M. \& Salzberg, S. L. Ultrafast and memoryefficient alignment of short DNA sequences to the human genome. Genome Biol. 10, R25 (2009).

163. O'Leary, N. A. et al. Reference sequence (RefSeq) database at NCBI: current status, taxonomic expansion, and functional annotation. Nucleic Acids Res. 44, D733-D745 (2016)

164. Andreev, D. E. et al. Oxygen and glucose deprivation induces widespread alterations in mRNA translation within 20 min. Genome Biol. 16, 90 (2015).

165. R Core Team. R: a language and environment for statistical computing. $R$ Foundation for Statistical Computing, Vienna, Austria. https://www.R-project. org/ (2020).

166. Andreev, D. E. et al. Translation of $5^{\prime}$ leaders is pervasive in genes resistant to eIF2 repression. eLife 4, e03971 (2015).

\section{Acknowledgements}

We would like to thank Melissa Benilous for administrative help, and members of the lab for continuous support and collaborative atmosphere. We like to thank members at the Scripps proteomics and genomic core for their help and expertise. This research was partially supported by a training grant in Alzheimer's drug discovery from the Lottie French Lewis Fund of the Community Foundation for Palm Beach and Martin Counties; grant awards from NIH/NINDS R01-NS087019-01A1, NIH/NINDS R01-NS09457701A1, and a grant from Cure for Huntington Disease Research Initiative (CHDI) foundation.

\section{Author contributions}

S.S made the initial observations and further conceptualized the project and revised the paper together with N.S., M.S., U.N.R.-J., and A.M. M.E. carried out polysome profiles, and related biochemical experiments, prepared volcano plots, and pause density graphs. P.P.K. generated cDNA library. E.R. and J.B. carried out bioinformatics and Ribo-Seq/mRNA-Seq overlap tracks on the UCSC Genome Browser using track hubs. A.M. generated the data for the triplet periodicity, metagene, pause analysis, the center of ribosome density, and differential gene expression analysis. N.S. carried out IP, additional polysome-related biochemical experiments, and analysis of the data. N.G. helped in Western blotting experiments. N.T.U. carried out STED imaging and colocalization analysis. M.S., U.N.R.-J., K.F., and J.F. supported in qPCR, profiling, and western blotting. S.S. analyzed the data and wrote the paper with input from co-authors.

\section{Competing interests}

The authors declare no competing interests.

\section{Additional information}

Supplementary information The online version contains supplementary material available at https://doi.org/10.1038/s41467-021-21637-y.

Correspondence and requests for materials should be addressed to S.S.

Peer review information Nature Communications thanks Toshifumi Inada and other, anonymous, reviewers for their contributions to the peer review of this work. Peer review reports are available.

Reprints and permission information is available at http://www.nature.com/reprints

Publisher's note Springer Nature remains neutral with regard to jurisdictional claims in published maps and institutional affiliations.

(c) (i) Open Access This article is licensed under a Creative Commons Attribution 4.0 International License, which permits use, sharing, adaptation, distribution and reproduction in any medium or format, as long as you give appropriate credit to the original author(s) and the source, provide a link to the Creative Commons license, and indicate if changes were made. The images or other third party material in this article are included in the article's Creative Commons license, unless indicated otherwise in a credit line to the material. If material is not included in the article's Creative Commons license and your intended use is not permitted by statutory regulation or exceeds the permitted use, you will need to obtain permission directly from the copyright holder. To view a copy of this license, visit http://creativecommons.org/ licenses/by/4.0/.

(C) The Author(s) 2021 